\title{
Remediation of heavy metal contaminated soil by biodegradable chelator-induced washing: Efficiencies and mechanisms
}

\author{
Guiyin Wang ${ }^{\mathrm{a}, \mathrm{c}, \mathrm{e}, 1}$, Xiaomei Pan ${ }^{\mathrm{a}, \mathrm{b}, 1}$, Shirong Zhang ${ }^{\mathrm{a}, \mathrm{c}, *}$, Qinmei Zhong ${ }^{\mathrm{a}, \mathrm{c}}$, Wei Zhou ${ }^{\mathrm{d}}$, \\ Xiaohong Zhang ${ }^{\mathrm{a}}$, Jun $\mathrm{Wu}^{\mathrm{a}}$, Martina G. Vijver ${ }^{\mathrm{e}}$, Willie J.G.M. Peijnenburg ${ }^{\mathrm{e}, \mathrm{f}}$ \\ ${ }^{a}$ College of Environmental Science, Sichuan Agricultural University, Wenjiang, 611130, China \\ ${ }^{\mathrm{b}}$ Chengdu Agricultural College, Wenjiang, 611130, China \\ ${ }^{\mathrm{c}}$ Sichuan Provincial Key Laboratory of Soil Environmental Protection, Chengdu, 611130, China \\ ${ }^{\mathrm{d}}$ College of Resources, Sichuan Agricultural University, Wenjiang, 611130, China \\ ${ }^{\mathrm{e}}$ Institute of Environmental Sciences (CML), Leiden University, P.O. Box 9518, 2300 RA, Leiden, the Netherlands \\ ${ }^{\mathrm{f}}$ National Institute of Public Health and the Environment (RIVM), P.O. Box 1, Bilthoven, the Netherlands
}

\section{A R T I C L E I N F O}

\section{Keywords:}

Soil washing

Biodegradable chelator

Heavy metal

Spectroscopic analysis

Contaminated soil

\begin{abstract}
A B S T R A C T
Biodegradable chelators (BCs) are promising substitutes for conventional washing agents in the remediation of heavy metal contaminated soil with strong complexing ability and less cost. However, great challenges for the applications of BC-assisted washing still exist, such as the assessment of the factor affecting the efficiency of metal removal and the unclear of the metal removal mechanism. Batch washing was therefore explored to evaluate the potential for four BCs for removing $\mathrm{Cd}, \mathrm{Pb}$, and $\mathrm{Zn}$ from polluted soils. The soil spectroscopic characteristics before and after washing were also investigated. The results demonstrated that iminodisuccinic acid (ISA) and glutamate-N, N-diacetic acid (GLDA) were an appealing alternative to commonly used non-biodegradable ethylenediaminetetraacetic acid, but glucomonocarbonic acid (GCA) and polyaspartic acid (PASP) were less efficient. Optimal parameters of BCs were determined to be a concentration of $50 \mathrm{mmol} \mathrm{L}^{-1}$, a $\mathrm{pH}$ of 5.0, a contact time of $120 \mathrm{~min}$, and a solid/liquid ratio of 1:5, considering metal removal efficiencies and the suitable cost. A single removal washing could be up to $52.39 \%$ of $\mathrm{Cd}, 71.79 \%$ of $\mathrm{Pb}$, and $34.13 \%$ of $\mathrm{Zn}$ from mine soil, and $98.28 \%$ of $\mathrm{Cd}, 91.10 \%$ of $\mathrm{Pb}$, and $90.91 \%$ of $\mathrm{Zn}$ from polluted farmland soil. After washing, the intensity of heavy metal binding to soil colloids increased while the metal mobility reduced because of weakly bound fractions removed by BCs. The BCs-induced soil washing revealed that the possible mechanisms of metal removal included the acid dissolution, ion exchange, and surface complexation. Our findings highlight the potential application of especially ISA and GLDA as efficient washing agents to remove potentially toxic elements from contaminated soils.
\end{abstract}

\section{Introduction}

Soil washing with chelators, a potential technology developed in recent years for rapid remediation of soil contaminated with potentially toxic elements (PTEs), is characterized by its simplicity of operation and remarkable efficiency (Ferraro et al., 2016; Gusiatin et al., 2017; Dolev et al., 2019; Piccolo et al., 2019). This technique employs physical processes to separate the polluted soil particles followed by chemical extraction with chelators to form coordinate bonds with PTEs and thus facilitates their solubilization from solid to solution (Borggaard et al., 2019; Kulikowska et al., 2019). During the last two decades, ethylenediaminetetraacetic acid (EDTA) has attracted amazing attention as washing agent because of its high metal extraction efficiency and the high solubility and the high thermodynamic stability of the formed metal-complexes (Chauhan et al., 2015; Wei et al., 2018; Cao et al., 2019; Rui et al., 2019). However, it shows an evident drawback of limited biodegradability and quite persistent in soils, thus contributing to potential adverse effects on soil functioning (Wu et al., 2015; Borggaard et al., 2019; Gluhar et al., 2019; Piccolo et al., 2019). The search for more eco-friendly biodegradable variants to substitute the classical chelants, therefore, becomes a hotspot for the decontamination of PTE-polluted soils.

Owing to less disruptive effects on the soil environment, some biodegradable chelators (BCs) like [S, S]-ethylenediaminedisuccinic

\footnotetext{
* Corresponding author. College of Environmental Science, Sichuan Agricultural University, Wenjiang, 611130, China.

E-mail address: srzhang01@aliyun.com (S. Zhang).

${ }^{1}$ These authors contributed equally to this work.
} 
acid (EDDS) have been highly proposed as an alternative for EDTA used in the soil washing process (Tandy et al., 2006; Beiyuan et al., 2017; Sanderson et al., 2017). In comparison with EDTA, EDDS has outstanding biodegradability with short half-lives of 4.18-5.60 days (Tandy et al., 2006) and low toxicity to soil microorganisms as well as negligible effects on plants (Beiyuan et al., 2018). Previous researches have confirmed that EDDS could effectively remove $\mathrm{Cd}, \mathrm{Zn}$, and $\mathrm{Cu}$ and diminish their leachability and bioaccessibility in remediated soils (Pinto et al., 2014; Liu et al., 2019). However, it was marginally effective for complexing with $\mathrm{Pb}$ compared with EDTA as evident from the significantly higher stability constant $\left(\log \mathrm{K}_{\mathrm{Pb}-\mathrm{EDTA}}=17.9>\log \right.$ $\mathrm{K}_{\mathrm{Pb}-\mathrm{EDDS}}=12.7$ ) (Begum et al., 2012; Beiyuan et al., 2018). This hampered the capacity of EDDS for decontamination of polluted soils. Besides, a relatively high price of EDDS (USD, 2000-5000 per ton, http://www.1688.com) becomes a stumbling stone to an economically feasible choice for the treatment processes (Beiyuan et al., 2017). Consequently, the interest of researchers moved to the use of the other BCs that are high performance, more economic feasibility, and wide applicability to address the aforementioned issues.

Glucomonocarbonic acid (GCA), glutamate-N,N-diacetic acid (GLDA), polyaspartic acid (PASP), and iminodisuccinic acid (ISA) have recently been introduced as biodegradable alternatives to EDTA, along with EDDS (Begum et al., 2012; Pinto et al., 2014; Wu et al., 2015; Wang et al., 2016; Mu Azu et al., 2018; Wang et al., 2018a,b; Wang et al., 2018a,b). They are water-soluble, non-toxic, and possess superior biodegradable characteristics within 28 d (Kołodyńska, 2011; Pinto et al., 2014; Suanon et al., 2016; Mu Azu et al., 2018), and therefore may be minimizing adverse effects of soil washing on soil functions. Their commercial production is based on green chemistry processes involving the fermentation, thermal polymerization, etc. The synthesis of BCs is environmentally attractive and cost-effective, allowing for mass production as compared with EDTA, EDDS or their homologs (Zeino et al., 2018; Verma and Hait, 2019). More importantly, these BCs contain abundant ligand functional groups such as carboxyl and amide that could be a powerful capacity to chelate polyvalent ions and thus potentially serve as green alternatives to soil remediation. We have previously explored the fate and toxicity of residual metals (Wang et al., 2018), the change in ecological function (Wang et al., 2016), and the reuse feasibility of washed soil (Wang et al., 2018) by these BCs. Different factors like concentrations, $\mathrm{pH}$ values, and durations could however affect their extraction efficiencies. The impacts of these factors on the metal extraction efficiency have not yet been sufficiently investigated but are essential for optimization purposes as well as understanding the mechanisms.

One of the most important aspects for BC-induced soil washing technique is to investigate the surface features of soil and to further reveal the washing mechanisms (Tang et al., 2017). Fortunately, the recent development of in situ non-destructive microsurgical techniques, such as Fourier transform infrared spectroscopy (FTIR), scanning electron microscopy equipped with an energy dispersive X-ray spectrometer (SEM-EDS), X-ray diffraction (XRD), and X-ray photoelectron spectrometry (XPS), provides a valuable opportunity in demonstrating the contaminant removal mechanisms. However, the application of these techniques involved soil washing remains limited (Tsang and Hartley, 2014; Wei et al., 2018). Previous reports confirmed by XPS that the combination of dithionite and EDTA greatly improved soil arsenic removal because iron oxides-bound heavy metals were transformed to $\mathrm{Fe}(\mathrm{II}, \mathrm{III})$ or $\mathrm{Fe}(\mathrm{II})$ oxide forms under the reduction of dithionite (Kim et al., 2015). The SEM-EDS, FTIR, and XRD elucidated that the predominant mechanisms of saponin enhance PTE removal from soil and sludge were complexation, metalbridging, and solubilization effects (Mukhopadhyay et al., 2015; Tang et al., 2017). Although some efforts in gathering soil spectroscopy characteristics were made during the process (Medina et al., 2017; Hisada and Kawase, 2018; Mu Azu et al., 2018), the available information concerning the metal removal mechanisms via soil washing is still limited especially for BCs such as GCA, GLDA, PASP, and ISA that are new and green alternatives of conventional chelating agents.

In this study, the potential for four BCs (GCA, GLDA, PASP, and ISA) was assessed as washing agents for the removal of heavy metals from contaminated soils. The objectives of the work were to: 1) examine the optimal operational conditions using the control factors including the concentrations and $\mathrm{pH}$ values of $\mathrm{BC}$ solution, contact times, and solid-to-liquid $(S / L)$ ratios for $\mathrm{Cd}, \mathrm{Pb}$, and $\mathrm{Zn}$ removal, and 2) determine the mechanisms of BCs for heavy metal removal via FTIR, SEM-EDS, XRD, and XPS assistant. This work here could devote substantial information and technical support for BCs as green and sustainable washing agent to clean soil polluted with PTEs.

\section{Materials and methods}

\subsection{Soil sample collection and characterization}

Two samples of genuinely contaminated soils were obtained from an abandoned mine smelting area (mine soil; $29^{\circ} 24^{\prime} \mathrm{N}, 102^{\circ} 39^{\prime} \mathrm{E}$ ) and a paddy field near a non-ferrous metal smelter (polluted farmland soil; $\left.30^{\circ} 59^{\prime} \mathrm{N}, 103^{\circ} 57^{\prime} \mathrm{E}\right)$ both in Sichuan Province, China. The collected top layer $(0-20 \mathrm{~cm})$ samples were air-dried, homogenized through a 10 -mesh nylon sieve, and subsequently stored at $4{ }^{\circ} \mathrm{C}$ for subsequent experiments. The texture of mine soil consisted of $40.2 \%$ sand, $7.6 \%$ silt, and $52.2 \%$ clay with $\mathrm{pH}$ ranged from 6.25 to 6.31 and organic carbon content of $19.2 \mathrm{~g} \mathrm{~kg}^{-1}$; while the polluted farmland soil contained $18.1 \%$ of sand, $16.7 \%$ of silt, and $65.2 \%$ of clay and had a relatively high concentration $\left(23.9 \mathrm{~g} \mathrm{~kg}^{-1}\right)$ of organic carbon and a near-neutral pH (6.97-7.16) (Wang et al., 2018; Wang et al., 2018). Microwave digestion system (GHZ-16, Beijing Guohuan Institute of High-tech Automation, China) with concentrated $\mathrm{HNO}_{3}$ was applied for heavy metal quantification in conjunction with a flame atomic absorption spectrophotometer (FAAS, Thermo Solaar M6, Thermo Fisher Scientific Ltd., USA). The $\mathrm{Cd}, \mathrm{Pb}$, and $\mathrm{Zn}$ concentrations were 18.34 , 1221.69 , and $2648.17 \mathrm{mg} \mathrm{kg}^{-1}$ in the mine soil and 42.91, 231.56, and $1285.73 \mathrm{mg} \mathrm{kg}^{-1}$ in the polluted farmland soil, respectively, all of which exceed the standard by 2-107 times, according to "Soil Environmental Quality-risk Control Standard for Soil Contamination of Agricultural Land (GB 15618-2018)".

\subsection{Batch soil washing experiments}

\subsubsection{Single-factor condition optimization experiments}

It is known that the initial concentrations and $\mathrm{pH}$ values of washing solution, contact times, and $S / L$ ratios are the most basic parameters in the removal of $\mathrm{Cd}, \mathrm{Pb}$, and $\mathrm{Zn}$ from polluted soil. The optimization of these parameters during the washing process could improve the removal behavior of soil $\mathrm{Cd}, \mathrm{Pb}$, and $\mathrm{Zn}$. Before the experiment, the $\mathrm{BC}$ (GCA, GLDA, PASP, and ISA, Fig. S1) solutions were freshly prepared and $200 \mathrm{mg} \mathrm{L}^{-1}$ of $\mathrm{NaN}_{3}(0.05-0.10 \mathrm{~mL})$ solutions were added to prevent biodegradation (Gan et al., 2017) followed by covering each solution with aluminum foil to avoid photodegradation (Beiyuan et al., 2018). In this study, to estimate the effects of initial BC concentrations on the metal removal efficiencies, 9 experiments representing different concentration levels of 1-100 mmol L ${ }^{-1}$ under condition of $\mathrm{pH}$ of 5.00 were conducted. Soils (10.00 g) were mixed with each BC washing solutions to acid-rinsed polyethylene tubes with $S / L$ ratio of $1: 10$. Subsequently, the mixed suspensions were stirred at room temperature with an oscillator (ZQPL-200, Tianjin Lai Bo Terry Instrument Equipment Co., Tianjin, China) at $170-180 \mathrm{rpm}$ for $60 \mathrm{~min}$. After centrifugation, the supernatants filtered through $0.45-\mu \mathrm{m}$ filters and the metal concentrations were determined by FAAS.

To determine the $\mathrm{pH}$ effects on metal removal, the initial $\mathrm{pH}$ values of each BC solution $\left(50 \mathrm{mmol} \mathrm{L}^{-1}\right)$ between were adjusted 3.0 to 9.0 using $0.01 \mathrm{~mol} \mathrm{~L}^{-1} \mathrm{HCl}$ or/and $\mathrm{NaOH}$ solutions. The $S / L$ ratio was fixed at 1:10. After shaking the mixed suspensions on an oscillator at the 
same speed of $170-180 \mathrm{rpm}$ for $60 \mathrm{~min}$, the samples were allowed to separate by centrifugation and membrane filtering and the metal concentration was detected.

To determine the effects of contact time, several experiments with different contact times (2-720 min), the initial concentrations of $\mathrm{BC}$ solution $50 \mathrm{mmol} \mathrm{L}^{-1}$, the $S / L$ ratio of $1: 10$ and the optimum $\mathrm{pH}$ were conducted in polyethylene tubes. After shaking, the suspensions were separated by centrifugation and membrane filtering and the metal concentration was detected.

To determine the effects of the $S / L$ ratio on metal removal, several tests were conducted at diverse $S / L$ ratios $(1: 2.5,1: 5,1: 7.5,1: 10,1: 15$, and 1:20); this was done at the optimum $\mathrm{pH}$ and the optimal contact time with $50 \mathrm{mmol} \mathrm{L}^{-1}$ of each BC solution in polyethylene tubes on the oscillator. The soils were separated by centrifugation and membrane filtering and the metal concentration in the supernatant was detected. Deionized water was employed as control and each treatment was conducted in triplicate. The $\mathrm{Cd}, \mathrm{Pb}$, and $\mathrm{Zn}$ removal efficiencies (\%) were calculated using Eq. (1).

Re movalefficiency $=\frac{C_{\text {solution }} \times V}{m \times C_{\text {total }}} \times 100 \%$

where $C_{\text {solution }}$ is the concentration of each metal ( $\mathrm{Cd}, \mathrm{Pb}$, and $\mathrm{Zn}$ ) in the washing solution ( $\left.\mathrm{mg} \mathrm{L}^{-1}\right) ; V$ is the volume of $\mathrm{BC}$ washing solution $(\mathrm{L})$; $m$ is the dry mass of soil (kg); $C_{\text {total }}$ is the total concentrations of $\mathrm{Cd}, \mathrm{Pb}$, and $\mathrm{Zn}$ in dry soil $\left(\mathrm{mg} \mathrm{kg}^{-1}\right)$.

\subsubsection{Sequential extraction experiments}

To clarify the change in the stability and mobility of heavy metals in soils before and after washing, a sequential extraction procedure of modified Tessier method (Tessier et al., 1979) was applied. Reagents with enhancing dissolution strength were applied to divide $\mathrm{Cd}, \mathrm{Pb}$, and Zn into six operationally-defined fractions named water-soluble, exchangeable, bound to carbonates, bound to Fe-Mn oxides, bound to organic matters, and residual fractions (Suanon et al., 2016). After each extraction, the extraction solutions were centrifuged at $4000 \mathrm{rpm}$ for $10 \mathrm{~min}$ and then filtered through $0.45-\mu \mathrm{m}$ filters. Metals from each sequential extraction procedure were quantified by FAAS. In addition, to distinguish effects of $\mathrm{pH}$ on chemical speciation and removal efficiency of heavy metal, the sequential extractions were also performed for the soil washed with GLDA and ISA under different $\mathrm{pH}$ (3.0, 5.0, 7.0, and 9.0). The index of $I_{R}$ (reduced partition index) and $M_{F}$ (metal bioavailability factor) before and after BC washing were calculated based on the results of sequential extraction procedure (Kulikowska et al., 2019; Yang and Hodson, 2019). The two indexes were calculated as follows:

$I_{R}=\left(\sum_{i=1}^{k} i^{2} \times F_{\mathrm{i}}\right) / k^{2}$

$M_{F}=\left(\sum_{\mathrm{i}=1}^{3}\right) F_{i}^{\prime} \times 100 \% / \sum_{\mathrm{i}=1}^{k} F_{i}^{\prime}$

where $i$ represents the number of the extraction step, $k$ value is 6 (for the modified Tessier method), $F_{i}(\%)$ is the percentage concentration of the considered metal in fraction $i$. The $I_{R}$ value ranged from 0 to $1 . F_{i}$, $\left(\mathrm{mg} \mathrm{kg}^{-1}\right.$ ) is actual concentration of the considered metal in fraction $i$.

\subsection{Spectroscopy analysis}

Soil samples, before and after washing with EDTA, GCA, GLDA, PASP, and ISA under the optimization conditions in section 2.2.1, were lyophilized for $48 \mathrm{~h}$ with a vacuum freeze-dryer (LGJ-10, Beijing Songyuanhuaxing Technologies, China). Subsequently, they were characterized by FTIR, SEM-EDS, XRD, and XPS. A detailed description of the spectroscopy analysis of washed soils is available in SI.

\subsection{Quality control and statistical analysis}

Glass and plastic vessels used in the work were presoaked in $20 \%$ $\mathrm{HNO}_{3}$ overnight. A certified soil reference material (GBW07405, National Research Centre for Certified Reference Materials of China) was performed to confirm the accuracy and precision of metal analytical processes. The recoveries of $\mathrm{Cd}, \mathrm{Pb}$, and $\mathrm{Zn}$ in the standard reference ranged from $95 \%$ to $107 \%$ for both sequential extraction and microwave digestion. Additionally, a continual calibration verification standard was determined after every 30 samples to maintain constant conditions during the FAAS analytical process.

Statistical analysis was conducted using SPSS version 19.0 (SPSS Inc., Chicago, IL, USA). Statistical differences of soil $\mathrm{Cd}, \mathrm{Pb}$, and $\mathrm{Zn}$ removal efficiencies under different washing conditions were analyzed with One-way ANOVA followed by Tukey tests at $P<0.05$. All graphs were created with OriginPro 9.0 (OriginLab, Northampton, MA, US). In addition, five kinetic models namely pseudo-first order, pseudo-second order, intraparticle diffusion, Elovich, and two-constant rate equation models have been employed to fit the kinetic data (Gusiatin et al., 2017; Golmaei et al., 2018; Yang and Hodson, 2019; Zhang et al., 2019). The coefficients of determination $\left(R^{2}\right)$ and root mean square errors (RMSE) were calculated to obtain the best-fitted kinetic model.

\section{Results and discussion}

\subsection{Optimization conditions of soil washing}

\subsubsection{Concentrations of biodegradable chelator}

The $\mathrm{Cd}, \mathrm{Pb}$, and $\mathrm{Zn}$ removal efficiencies from both the mine soil and the polluted farmland soil increased sharply with $\mathrm{BC}$ concentrations up to $25 \mathrm{mmol} \mathrm{L}^{-1}(P<0.05)$, then increased slightly from $25 \mathrm{mmol} \mathrm{L}^{-1}$ to $50 \mathrm{mmol} \mathrm{L}^{-1}$ (Fig. $1, P<0.05$ ). However, their increases were not significant above BC concentrations of $50 \mathrm{mmol} \mathrm{L}^{-1}(P>0.05)$. Higher $\mathrm{BC}$ concentrations failed to contribute to the enhancement of the soil $\mathrm{Cd}, \mathrm{Pb}$, and $\mathrm{Zn}$ removal. These results were similar to those acquired for synthetic humic-like acid (Yang and Hodson, 2019), potassium lignosulfonate (Liu et al., 2019), and dissolved organic matter (Kulikowska et al., 2019) as washing agents. Among the four tested BCs, GLDA and ISA demonstrated huge capabilities to bind metal ions compared with PASP and GCA. This is attributed to the higher amount and the type of functional groups in GLDA and ISA (Fig. S1), which even at low concentrations enable the efficient formation of soluble metal-chelant complexes (Tsang and Hartley, 2014; Ferraro et al., 2016; Wang et al., 2018). The $\mathrm{Cd}, \mathrm{Pb}$, and $\mathrm{Zn}$ removal for mine soil were $34.63,58.85$, and $25.55 \%$ after washing with GLDA, and reached $11.83,34.26$, and $20.96 \%$ by ISA washing, respectively. While the metal removal efficiencies from the polluted farmland soil (48.89-85.46\%) were obviously higher than those from the mine soil. The metals in polluted farmland soil may be more closely associated with organic matter and clay (Zhang et al., 2019). For the mine soil, a higher fraction of metals was incorporated within the residual fractions (Zhang et al., 2019). The available binding sites for the formation of metal-chelant complexes increased with the increase of BC concentration (Ferraro et al., 2016).

\subsection{2. $\mathrm{pH}$ of biodegradable chelator solution}

The soil $\mathrm{Cd}, \mathrm{Pb}$, and $\mathrm{Zn}$ removal efficiencies were highly pH-dependent (Fig. 2). Regardless of the type of BC and polluted soil, metal removal was more higher under acidic than under alkaline conditions. A remarkable decreasing trend of metal removal efficiency with increasing $\mathrm{pH}$ from 3.0 to 5.0 was observed $(P<0.05)$. On the other hand, the efficiency decreased slightly from $\mathrm{pH} 5.0$ to 7.0 and subsequently approached a relatively constant level in both the soils $(P>0.05)$. In particular, the highest removal of $\mathrm{Cd}, \mathrm{Pb}$, and $\mathrm{Zn}$ occurred at pH 3.0 with GLDA washing followed by ISA washing. The removal efficiencies of the former were $44.55,68.04$, and $28.94 \%$ from 

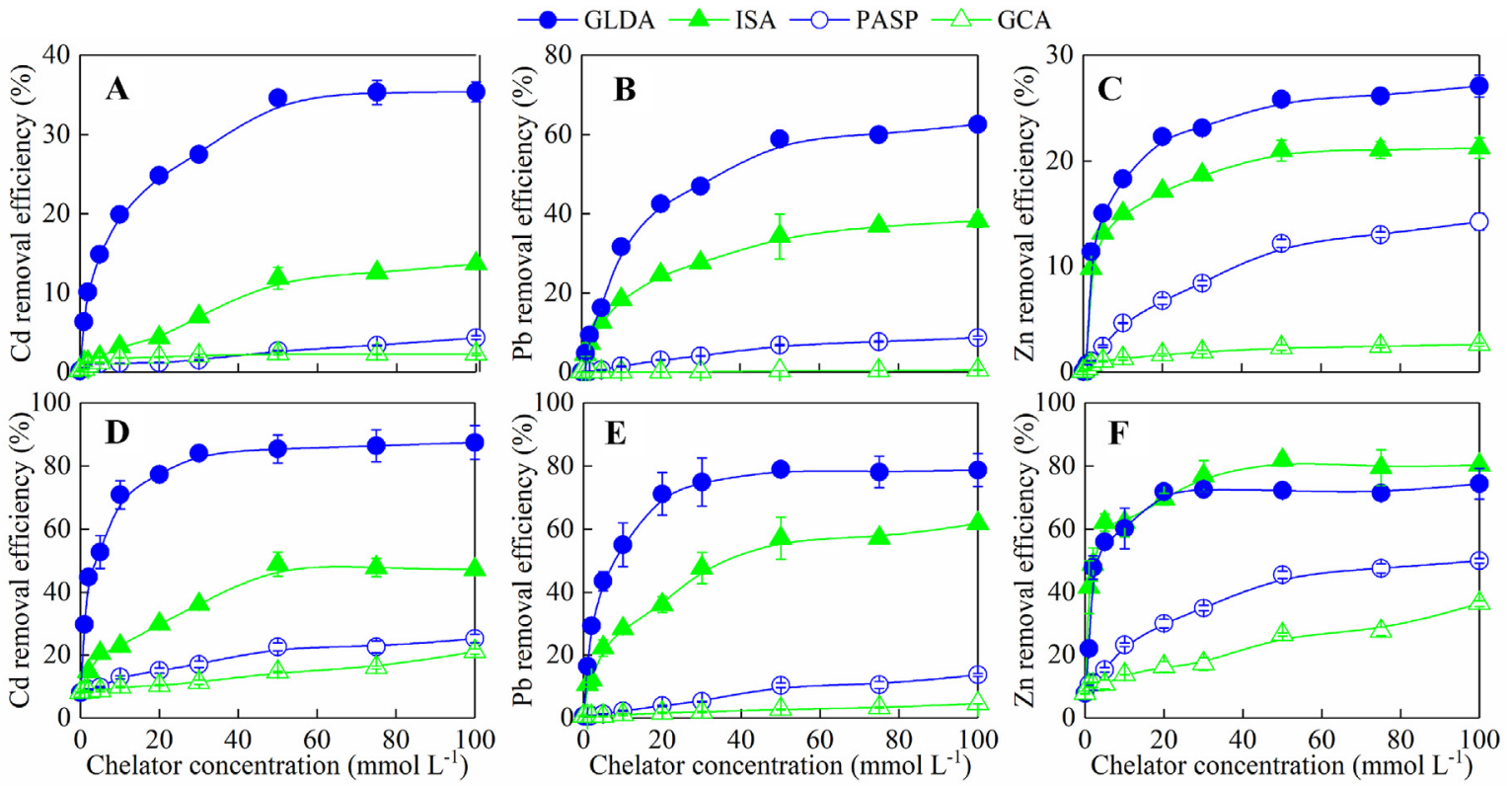

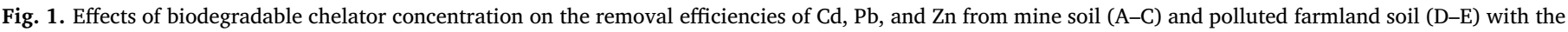

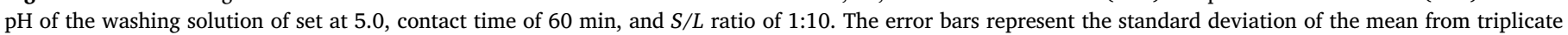
samples. PASP, polyaspartic acid; ISA, iminodisuccinic acid; GLDA, glutamate-N, N-diacetic acid; GCA, glucomonocarbonic acid.

mine soil and $86.07,91.10$, and $83.17 \%$ from polluted farmland soil, respectively.

To verify how $\mathrm{pH}$ affects heavy metal removal, the chemical fractionations of $\mathrm{Cd}, \mathrm{Pb}$, and $\mathrm{Zn}$ in soils after GLDA and ISA washing under different $\mathrm{pH}$ conditions were examined. As shown in Fig. S2, the metal fractions were found to vary with metals types. The $\mathrm{Cd}$ in the original mine soil and farmland soil was dominantly in the exchangeable, the carbonate bound, and residual fractions, which cumulatively accounted for about $80 \%$. The main fractions of $\mathrm{Pb}$ were the carbonate bound (57.35\%) and residual (26.03\%) fractions in the mine soil, whereas the carbonate bound $(39.15 \%)$, residual $(29.06 \%)$, and exchangeable
(15.77\%) fractions were predominant in the farmland soil. As for Zn, the carbonate bound, organic matter bound, and residual fractions took a large proportion in both soils, making it harder for $\mathrm{Zn}$ to be motivated.

Fig. S2 also showed that soil washing altered the chemical fractions of the residual $\mathrm{Cd}, \mathrm{Pb}$, and $\mathrm{Zn}$ under different $\mathrm{pH}$ conditions in both washed soils, thus leading to differentiated metal removal efficiencies. Compared to the original soil, all chemical fractions of $\mathrm{Cd}, \mathrm{Pb}$, and $\mathrm{Zn}$ in washed soils under different $\mathrm{pH}$ conditions were decreased. The magnitude of their reduction decreased with the increase of $\mathrm{pH}$. The water-soluble, exchangeable, and carbonate bound fractions were most
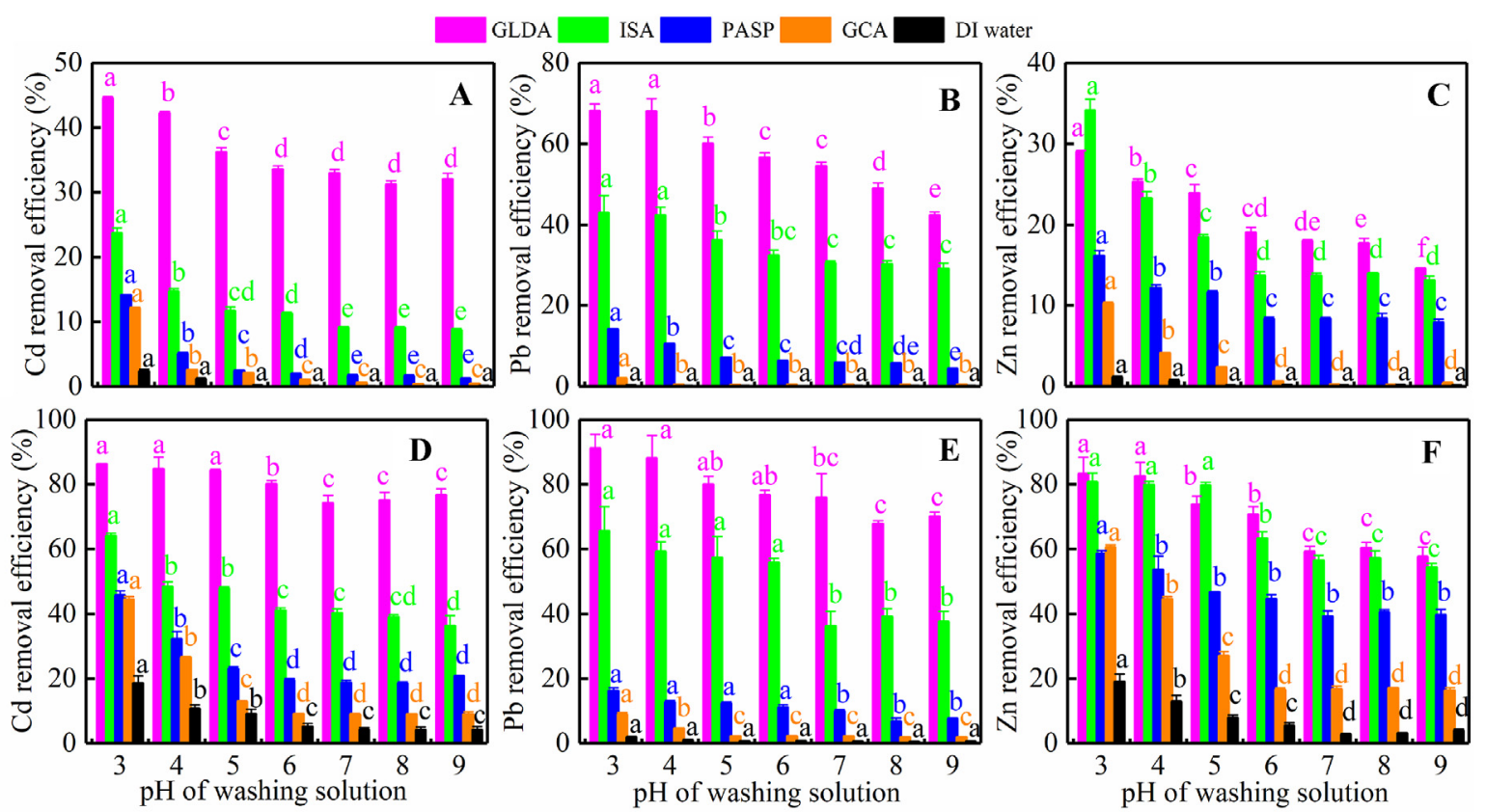

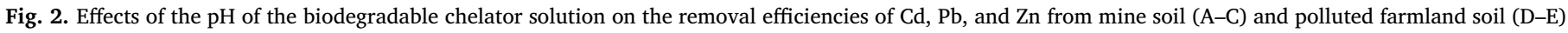

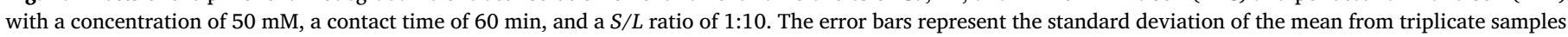

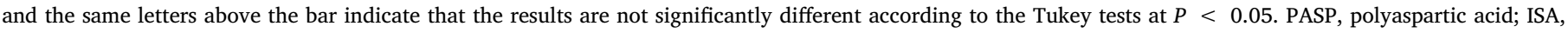
iminodisuccinic acid; GLDA, glutamate-N, N-diacetic acid; GCA, glucomonocarbonic acid. 
efficiently washed by GLDA and ISA, especially in the $\mathrm{pH}$ of 3.0 and 5.0, which was the same as the research results of commonly used eluents, such as EDTA and citric acid (Begum et al., 2012 ; ; Suanon et al., 2016; Hasegawa et al., 2019). Given that these metal fractions are unstable and sensitive to the change of environmental conditions, causing them to be easily extracted, which explains their low content in the washed soils (Wang et al., 2019; Dolev et al., 2020). However, metals with Fe-Mn oxide-bound, organically bound, and residual fractions are relatively stable that can be partly extracted (Begum et al., 2020; Feng et al., 2020). The above results indicated that GLDA and ISA could effectively removal heavy metals under different $\mathrm{pH}$ conditions, which is closely related to the change in the metal forms distribution during the washing process.

\subsubsection{Contact time and desorption kinetic}

In this study, the soil $\mathrm{Cd}, \mathrm{Pb}$, and $\mathrm{Zn}$ removal efficiencies increased dramatically during the first $60 \mathrm{~min}$ of washing $(P<0.05)$ and then slowly increased to equilibrium which was around $120 \mathrm{~min}$ in all cases (Fig. S3). A further increase of the washing time to $720 \mathrm{~min}$ had little effect on the overall removal efficiencies. These results demonstrated that the removal of soil $\mathrm{Cd}, \mathrm{Pb}$, and $\mathrm{Zn}$ from the mine soil and the polluted farmland soil by washing with BCs occurred in two phases: rapid removal within $120 \mathrm{~min}$ followed by gradual removal. This was in accordance with Kulikowska et al. (2019), who found that $\mathrm{Cu}, \mathrm{Pb}$, and $\mathrm{Zn}$ removal from soil with dissolved organic matter recovered from sewage sludge proceeded in two-step kinetic processes. This phenomenon was related to the less labile species for complexation with BCs (Kirpichtchikova et al., 2006) that occurred at the beginning of the process and the fast formation and release of Ca-chelant and other metal-chelant complexes from the soils (Wang et al., 2016; Golmaei et al., 2018). While the following extraction efficiencies were predominantly relied on the replenishment of the labile pool with recalcitrant species (Kirpichtchikova et al., 2006) and the capacity of mass transfer between the massive solution and soil particle surface (Tang et al., 2017). The removal efficiencies for each metal at $120 \mathrm{~min}$ were just $0.01-12.50 \%$ lower than at $720 \mathrm{~min}$. Considering the practical application of soil washing with BCs, thus, a contact time of 120 min would be a better choice.

Five kinetic models were further adopted to describe the soil $\mathrm{Cd}, \mathrm{Pb}$, and $\mathrm{Zn}$ removal process and the fitted results were evaluated by comparing the $R^{2}$ and RMSE (Table S1). Among them, both of pseudo-first order and pseudo-second order equations could be regarded as the satisfactory fitting models to describe the desorption of $\mathrm{Cd}, \mathrm{Pb}$, and $\mathrm{Zn}$ by BCs (Fig. 3), for the $R^{2}$ level closed to 1.0 and relatively low RMSE values. It suggested that the desorption mechanism of soil $\mathrm{Cd}, \mathrm{Pb}$, and $\mathrm{Zn}$ by BCs-induced washing involved both chemisorption-controlled process (Meng et al., 2017) and the sorption process of a physical nature (Długosz and Banach, 2018).

In addition, the calculated desorption capacity $\left(q_{e-\text { model }}\right)$ values were similar to the experimental measuring values $\left(q_{e-\exp }\right)$ (Table 1$)$, indicating that the washing processes of $\mathrm{Cd}, \mathrm{Pb}$, and $\mathrm{Zn}$ obeyed these two models, but depended on the types of metals and BCs for the entire washing period. Moreover, the $k_{2}$ (the pseudo-second order rate constant, $\mathrm{kg} \mathrm{mg}^{-1} \mathrm{~min}^{-1}$ ) values of $\mathrm{Cd}$ in both soils were at least one magnitude higher than those of $\mathrm{Pb}$ and $\mathrm{Zn}$, regardless of the species of BCs, implying that Cd should be the most mobile element in soil. This may be one of the reasons why $\mathrm{Cd}$ is of the most concern in the soil of south China (Kulikowska et al., 2015).

\subsection{4. $S / L$ ratio}

For both mine soil and polluted farmland soil, the $\mathrm{Cd}, \mathrm{Pb}$, and $\mathrm{Zn}$ removal efficiencies generally increased with a decreasing $S / L$ ratio (Fig. S4, $P<0.05$ ), as more ligands were available at a higher $S / L$ ratio. The metal removal efficiencies were $0.03-0.14 \%, 0.87-6.26 \%$, 6.55-25.73\%, and $21.56-45.94 \%$ from mine soil by GCA, PASP, ISA, and GLDA washing at $S / L$ ratio of $1: 2.5$, respectively, while they reached $\quad 0.69-14.77 \%, \quad 1.26-28.91 \%, \quad 38.41-70.24 \%$, and $72.32-76.37 \%$ from polluted farmland soil. The metal removal efficiencies reached the maximum level at $S / L$ ratio of $1: 20$, as they were relied, to a great extent, on the molar ratio of metals to washing reagents (Suanon et al., 2016). A low $S / L$ ratio triggers insufficient mixing between washing agent and soil, and causes the reaction system pulpous, and may increase the removal efficiencies considerably (Tang et al., 2017; Golmaei et al., 2018; Verma and Hait, 2019). However, when the $S / L$ ratio changed from 1:5 to $1: 20$, the metal removal rates were enhanced by less than $15.00 \%$ (except for $\mathrm{Pb}$ removal by ISA from mine soil and by PASP from polluted farmland soil). Decreasing the $S / L$ ratio could contribute to enhancing the metal removal, but higher $S / L$ ratio would inevitably consume large amounts of water and energy, increase the operating pressure of equipment, and generate more residual metal-bearing wastewater for subsequent treatment (Meng et al., 2017; Yang and Hodson, 2019). Consequently, A $S / L$ ratio of 1:5 was highly recommended to make practical applications of this potential technology cost-effective (Im et al., 2015; Jho et al., 2015; Wang et al., 2018).

\subsection{Effect of biodegradable chelator washing on heavy metal binding intensity and mobility in soil}

Decreasing heavy metal concentrations to meet agricultural utilization standards for reuse is a crucial remediation objective, however, much more attention should be paid to the environmental risks caused by the presence of mobile metal fractions (Wang et al., 2018; Shen et al., 2019). The $I_{R}$ and $M_{F}$ values (Fig. 4) were calculated to evaluate the stability and mobility of residual heavy metals. The $I_{R}$ value closed to 1.0 represents a high proportion of the metal being strongly bound in the residual fraction in which indicates minimal potential environmental risk (Tang et al., 2017; Yang and Hodson, 2019). Whereas, a low value of $I_{R}$ (close to zero) represents much of the metal resides in the soluble and exchangeable fraction, which suggests relatively high environmental risk (Tang et al., 2017; Yang and Hodson, 2019). High $M_{F}$ value has been exhibited the relatively easy mobility and the high biological availability of heavy metals in soils (Tang et al., 2017; Yang and Hodson, 2019).

The $I_{R}$ values of $\mathrm{Cd}$ and $\mathrm{Pb}$ in bulk soils were similar (0.45-0.51), whereas that of $\mathrm{Zn}$ was higher (0.61-0.73). Overall, they increased after BC washing $(P<0.05)$, suggesting that the metal fractions remaining in the remediated soils were more stable and impregnably bound to solid-phase components, thus declining their potential mobility and bioavailability. Especially, after ISA washing, the largest $I_{R}$ values of Cd and $\mathrm{Zn}$ in mine soil reached 0.57 and $0.90(P<0.05)$, respectively, and whereas that of $\mathrm{Pb}$ varied in a small range $(P>0.05)$. Changes in the $I_{R}$ values of $\mathrm{Pb}$ were not remarkable in which was consistent with the results of Kulikowska et al. (2019), demonstrating that the stable (bound to Fe-Mn oxides, bound to organic matters, and residual) fractions of $\mathrm{Pb}$ were still difficult to remove. Similarly, $\mathrm{Cd}$ in polluted farmland soil had the largest $I_{R}$ values after GLDA washing, whereas both of $\mathrm{Pb}$ and $\mathrm{Zn}$ had the largest $I_{R}$ values after EDTA treatment followed by GLDA treatment.

In addition, the $I_{R}$ values were also intimately connected with the $M_{F}$ values. While the $M_{F}$ values were more sensitive than $I_{R}$ values to account for the variation of the weak fraction during the BC-induced washing (Tang et al., 2017). Fig. 4D-F shows the $M_{F}$ values of soil Cd, $\mathrm{Pb}$, and $\mathrm{Zn}$ which shows clear differences in the before and after washing. The $M_{F}$ values for $\mathrm{Cd}$ and $\mathrm{Pb}(53.25-60.12 \%)$ both in initial mine soil and polluted farmland soil were higher than that of $\mathrm{Zn}$ (25.78-333.62\%, $P<0.05$ ). The results showed that the mobility of $\mathrm{Cd}$ and $\mathrm{Pb}$ were relatively high. Due to they were mainly associate with exchangeable and carbonate-bound fractions (Wang et al., 2018). After washing, the lowest $M_{F}$ values of $\mathrm{Cd}$ and $\mathrm{Pb}$ were 40.00 and $48.26 \%$ from mine soil, respectively, and 39.36 and $41.54 \%$ from polluted farmland soil after GIDA washing. While the lowest $\mathrm{Zn} M_{F}$ values were 


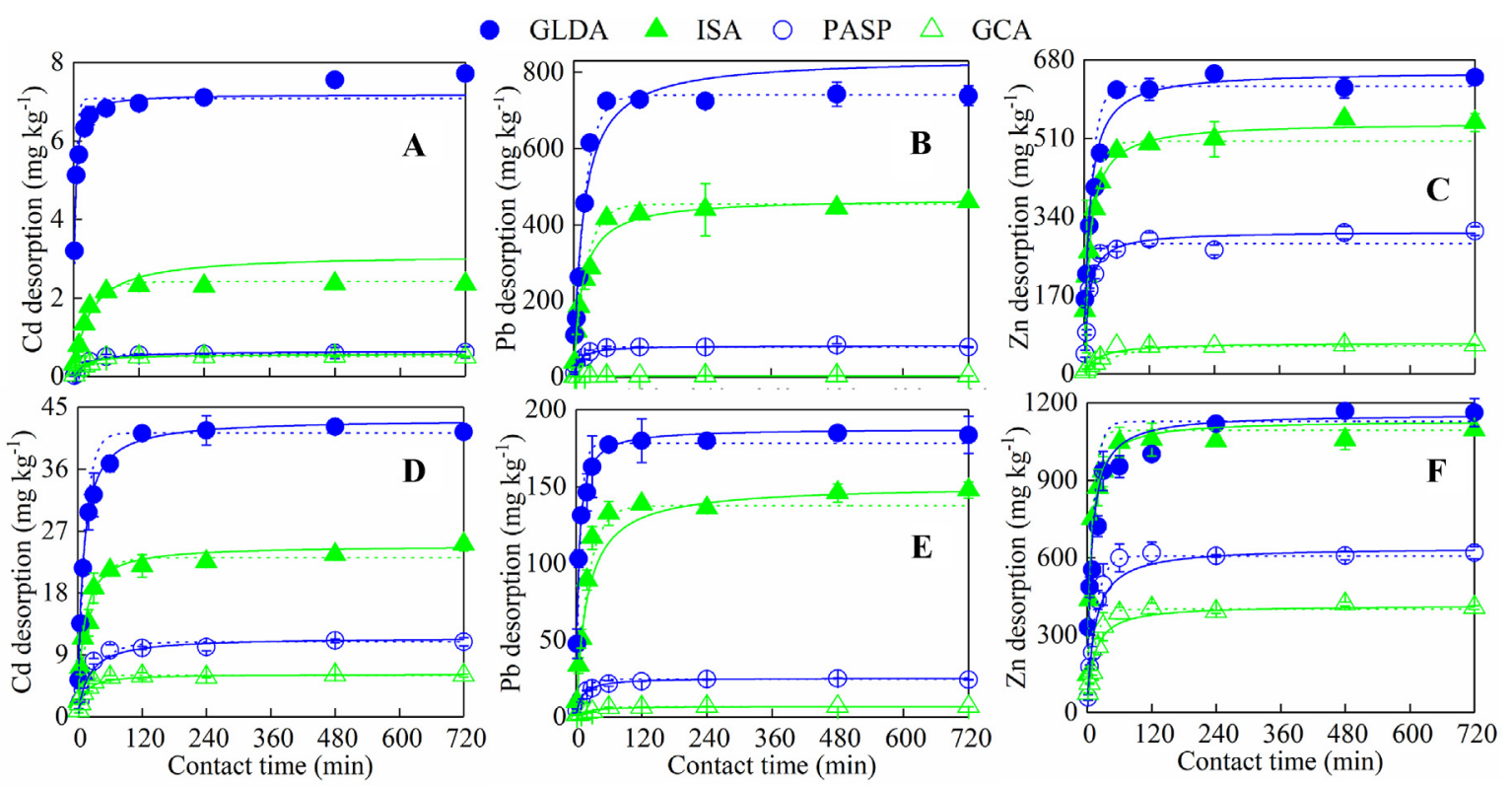

Fig. 3. Pseudo first-order kinetics (dotted line) and pseudo second-order kinetics (solid line) fittings for $\mathrm{Cd}, \mathrm{Pb}$, and $\mathrm{Zn}$ desorption within the presence of biodegradable chelator solution in batch experiments from mine soil (A-C) and polluted farmland soil (D-E) with a biodegradable chelator concentration of $50 \mathrm{mM}$, a pH washing solution of 5.0, and a $S / L$ ratio of 1:10. The error bars represent the standard deviation of the mean from triplicate samples. PASP, polyaspartic acid; ISA, iminodisuccinic acid; GLDA, glutamate-N, N-diacetic acid; GCA, glucomonocarbonic acid.

found in EDTA treatment. The obtained $M_{F}$ values confirmed the low removal efficiencies for metals in stable fractions and the immobile fractions predominantly presented in the washed soils. These results reflected that $\mathrm{BC}$-induced washing reduced the environmental risk caused by soil residual metals in mobile fractions that entered into the plants or food chain.

\subsection{Spectral characteristics of soils before and after washing}

\subsubsection{FTIR}

In the spectra of the bulk soils (Fig. 5 and Table S2), an absorbance at $3700-3100 \mathrm{~cm}^{-1}$, with a peak centered at 3620 and $3440 \mathrm{~cm}^{-1}$, could be attributed to the overlapping of $\mathrm{O}-\mathrm{H}$ stretching (Mukhopadhyay et al., 2015; Wei et al., 2018). A strong broadband observed at 3023 and $2899 \mathrm{~cm}^{-1}$ in the mine soil is assigned to stretch $(-\mathrm{CH})$ of $-\mathrm{CH}_{2}$ and- $\mathrm{CH}_{3}$ groups of aliphatic chains (Abou-El-Sherbini et al., 2017; Parolo et al., 2017). The absorption peaks at 2524, 1438,

Table 1

Kinetics parameters for $\mathrm{Cd}, \mathrm{Pb}$, and $\mathrm{Zn}$ desorption from contaminated soils after addition of the biodegradable chelator solutions. PASP, polyaspartic acid; ISA, iminodisuccinic acid; GLDA, glutamate-N, N-diacetic acid; GCA, glucomonocarbonic acid.

\begin{tabular}{|c|c|c|c|c|c|c|c|}
\hline \multirow[t]{2}{*}{ Soils } & \multirow[t]{2}{*}{ Treatments } & \multirow[t]{2}{*}{ Metals } & \multirow[t]{2}{*}{$q_{e-\exp }\left(\mathrm{mg} \mathrm{kg}^{-1}\right)$} & \multicolumn{2}{|c|}{ Pseudo-first order } & \multicolumn{2}{|l|}{ Pseudo-second order } \\
\hline & & & & $k_{1}\left(\min ^{-1}\right)$ & $q_{e-m o d e l}\left(\mathrm{mg} \mathrm{kg}^{-1}\right)$ & $k_{2}\left(\mathrm{mg} \mathrm{kg}^{-1} \min ^{-1}\right)$ & $q_{\text {e-model }}\left(\mathrm{mg} \mathrm{kg}^{-1}\right)$ \\
\hline \multirow[t]{12}{*}{ Mine soil } & \multirow[t]{3}{*}{ PASP } & $\mathrm{Cd}$ & 0.61 & $3.46 \times 10^{-2}$ & 0.59 & $6.91 \times 10^{-2}$ & 0.64 \\
\hline & & $\mathrm{Pb}$ & 78.31 & $6.68 \times 10^{-2}$ & 79.08 & $1.18 \times 10^{-3}$ & 84.07 \\
\hline & & $\mathrm{Zn}$ & 309.22 & $8.14 \times 10^{-2}$ & 288.39 & $3.78 \times 10^{-4}$ & 307.81 \\
\hline & \multirow[t]{3}{*}{ ISA } & $\mathrm{Cd}$ & 2.35 & $4.38 \times 10^{-2}$ & 2.34 & $2.37 \times 10^{-2}$ & 2.52 \\
\hline & & $\mathrm{Pb}$ & 460.45 & $4.40 \times 10^{-2}$ & 442.06 & $1.32 \times 10^{-4}$ & 474.42 \\
\hline & & $\mathrm{Zn}$ & 543.93 & $7.25 \times 10^{-2}$ & 511.37 & $2.05 \times 10^{-4}$ & 542.85 \\
\hline & \multirow[t]{3}{*}{ GLDA } & $\mathrm{Cd}$ & 7.71 & $2.54 \times 10^{-1}$ & 6.96 & $5.35 \times 10^{-2}$ & 7.32 \\
\hline & & $\mathrm{Pb}$ & 738.63 & $5.08 \times 10^{-2}$ & 740.02 & $0.90 \times 10^{-4}$ & 792.64 \\
\hline & & $\mathrm{Zn}$ & 642.36 & $6.34 \times 10^{-2}$ & 623.23 & $1.52 \times 10^{-4}$ & 658.98 \\
\hline & \multirow[t]{3}{*}{ GCA } & $\mathrm{Cd}$ & 0.50 & $4.13 \times 10^{-2}$ & 0.50 & $1.10 \times 10^{-1}$ & 0.54 \\
\hline & & $\mathrm{Pb}$ & 3.58 & $4.66 \times 10^{-2}$ & 3.34 & $2.11 \times 10^{-2}$ & 3.55 \\
\hline & & $\mathrm{Zn}$ & 62.06 & $3.04 \times 10^{-2}$ & 62.01 & $5.85 \times 10^{-4}$ & 67.63 \\
\hline \multirow[t]{12}{*}{ Farmland soil } & \multirow[t]{3}{*}{ PASP } & $\mathrm{Cd}$ & 10.89 & $4.27 \times 10^{-2}$ & 10.53 & $5.14 \times 10^{-3}$ & 11.37 \\
\hline & & $\mathrm{Pb}$ & 24.30 & $6.69 \times 10^{-2}$ & 23.68 & $3.87 \times 10^{-3}$ & 25.29 \\
\hline & & $\mathrm{Zn}$ & 629.32 & $5.64 \times 10^{-2}$ & 615.45 & $1.23 \times 10^{-4}$ & 657.32 \\
\hline & \multirow[t]{3}{*}{ ISA } & $\mathrm{Cd}$ & 25.09 & $5.61 \times 10^{-2}$ & 23.02 & $3.21 \times 10^{-3}$ & 24.69 \\
\hline & & $\mathrm{Pb}$ & 147.77 & $5.00 \times 10^{-2}$ & 142.23 & $4.42 \times 10^{-4}$ & 153.25 \\
\hline & & $\mathrm{Zn}$ & 1049.71 & $1.04 \times 10^{-1}$ & 1049.65 & $1.35 \times 10^{-4}$ & 1115.49 \\
\hline & \multirow[t]{3}{*}{ GLDA } & $\mathrm{Cd}$ & 41.38 & $6.76 \times 10^{-2}$ & 40.53 & $2.25 \times 10^{-3}$ & 43.31 \\
\hline & & $\mathrm{Pb}$ & 183.53 & $1.45 \times 10^{-1}$ & 175.96 & $1.17 \times 10^{-3}$ & 186.24 \\
\hline & & $\mathrm{Zn}$ & 1162.17 & $7.80 \times 10^{-2}$ & 1069.68 & $1.05 \times 10^{-4}$ & 1136.83 \\
\hline & \multirow[t]{3}{*}{ GCA } & $\mathrm{Cd}$ & 5.99 & $7.42 \times 10^{-2}$ & 5.86 & $1.74 \times 10^{-2}$ & 6.24 \\
\hline & & $\mathrm{Pb}$ & 6.76 & $2.95 \times 10^{-2}$ & 6.75 & $5.50 \times 10^{-3}$ & 7.32 \\
\hline & & $\mathrm{Zn}$ & 406.42 & $5.39 \times 10^{-2}$ & 403.98 & $1.80 \times 10^{-4}$ & 431.43 \\
\hline
\end{tabular}



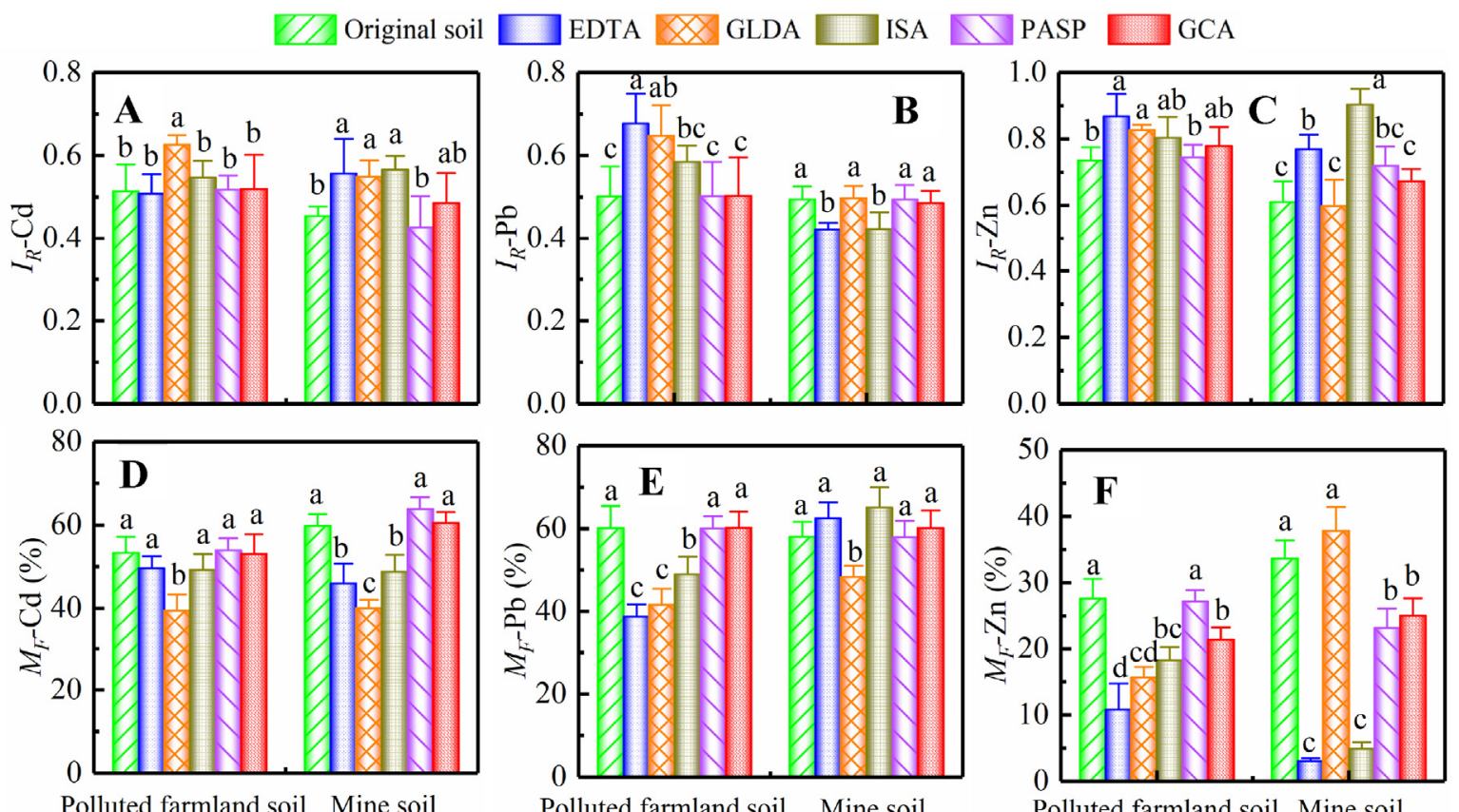

Fig. 4. Reduced partition index $\left(I_{R}, \mathrm{~A}-\mathrm{C}\right)$ and mobility $\left(M_{F}, \mathrm{D}-\mathrm{F}\right)$ variations for heavy metals in soil before and after washing with biodegradable chelator. The error bars represent the standard deviation of the mean from triplicate samples and the same letters above the bar indicate that the results are not significantly different according to the Tukey tests at $P<0.05$. PASP, polyaspartic acid; ISA, iminodisuccinic acid; GLDA, glutamate-N, N-diacetic acid; GCA, glucomonocarbonic acid.
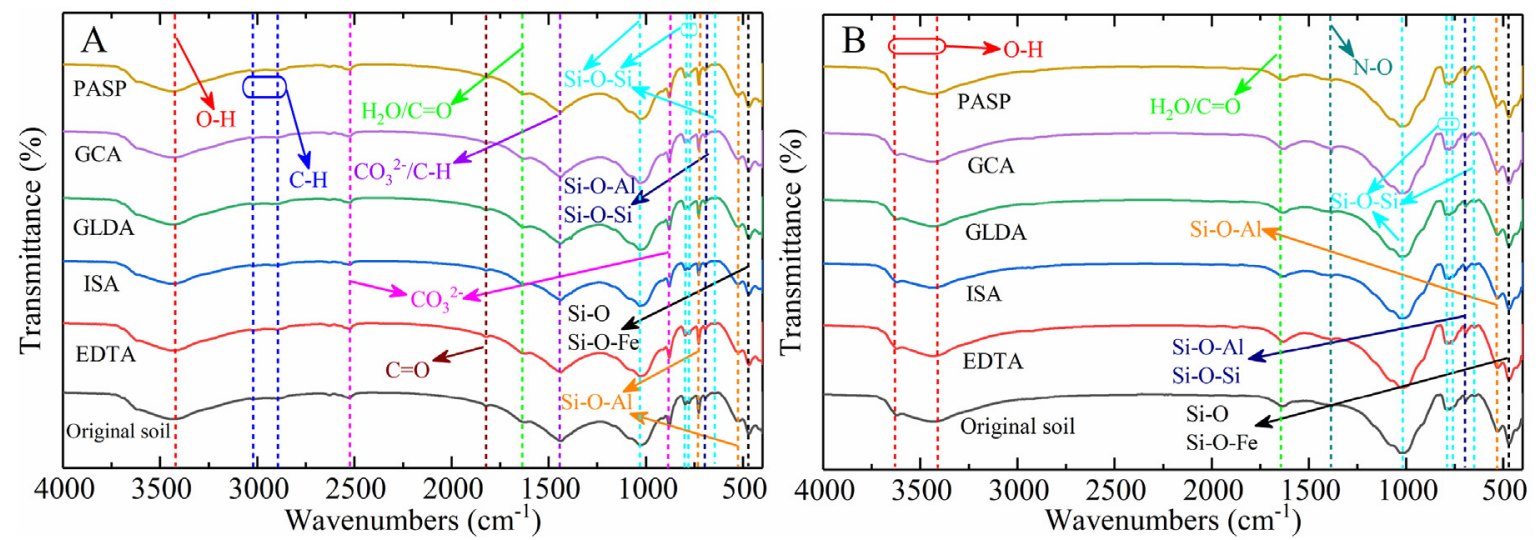

Fig. 5. FT-IR spectra of mine soil (A) and polluted farmland soil (B) samples before and after biodegradable chelator washing with a chelator concentration of $50 \mathrm{mM}$, a pH of 5.0, a contact time of $120 \mathrm{~min}$, and a $S / L$ ratio of 1:5. The spectra patterns are displaced equally along the $y$ axis. PASP, polyaspartic acid; ISA, iminodisuccinic acid; GLDA, glutamate-N, N-diacetic acid; GCA, glucomonocarbonic acid.

and $880 \mathrm{~cm}^{-1}$ corresponded to $\mathrm{CO}_{3}{ }^{2-}$ stretching vibrations (Parolo et al., 2017). The carboxylic $\mathrm{C}=\mathrm{O}$ stretching and/or water association with clay are reflected by peaks at 1825 and $1635-1615 \mathrm{~cm}^{-1}$ (Mu Azu et al., 2018; Wen et al., 2018). The peak around $1384 \mathrm{~cm}^{-1}$ in polluted farmland soil belongs to the $\mathrm{N}-\mathrm{O}$ stretching vibration of nitrates (Parolo et al., 2017). Stretch band peaks are observed at 1030-1028, 800-780, $729,694,648,529-523$, and $471-470 \mathrm{~cm}^{-1}$, which are indicative of in-plane $\mathrm{Si} / \mathrm{Fe}-\mathrm{O}$ bending vibrations, presence of $\mathrm{Si}-\mathrm{O}-\mathrm{Si}$ inter-tetrahedral bridging bonds, Si-O-Al deformation, and $\mathrm{Si}-\mathrm{O} / \mathrm{Si}-\mathrm{O}-\mathrm{Fe}$ bending vibrations (Tsang and Hartley, 2014; Wei and Chen, 2016; Medina et al., 2017; Wei et al., 2018). The results indicated that both soils were composed of mixed composites of $\mathrm{Si} / \mathrm{Fe} / \mathrm{Al}$ oxides.

In comparison with the spectrum of the bulk soils (Fig. 5 and Table S2), no additional peaks were observed in the remediated soils, indicating that the $\mathrm{BC}$-induced washing was capable of removing the heavy metals with limited effect on the solid surface. However, the $\mathrm{O}-\mathrm{H},-\mathrm{CH}$, and $\mathrm{C}=\mathrm{O}$ stretching vibrations shifted to a lower wavelength, due to the heavy metal ions reacting with BCs, and then being transferred into the solution. Moreover, the intensity of $\mathrm{Si} / \mathrm{Fe}-\mathrm{O}$ asymmetric and $\mathrm{Si}-\mathrm{O}-\mathrm{Al}$ stretching vibrations became weak. These changes indicated that $\mathrm{BC}$-induced washing promoted the dissolution of metal-Si/Fe/Al oxides, which permitted the surface characteristics of washed soils to be more noticeable in the FTIR spectra.

\subsubsection{SEM-EDS}

The original mine soil had a block and loosely bound structure, with an irregular and rough surface (Fig. 6A), while the original farmland soil showed a compact and sheet structure, with irregular gaps and uneven surface (Fig. S5A). After washing by EDTA and BCs, both types of soil particles were broken down to smaller granules with looser structure and smoother surface. This is similar to previous findings (Mukhopadhyay et al., 2015; Tang et al., 2017). Such striking changes in soil structure could be attributed to the dissolution of soluble salts and hydraulic flushing (Li et al., 2018a), which partially destructed the soil surface structure and produced a looser one. Moreover, the metal fractions also altered because of the broken particles and minerals 

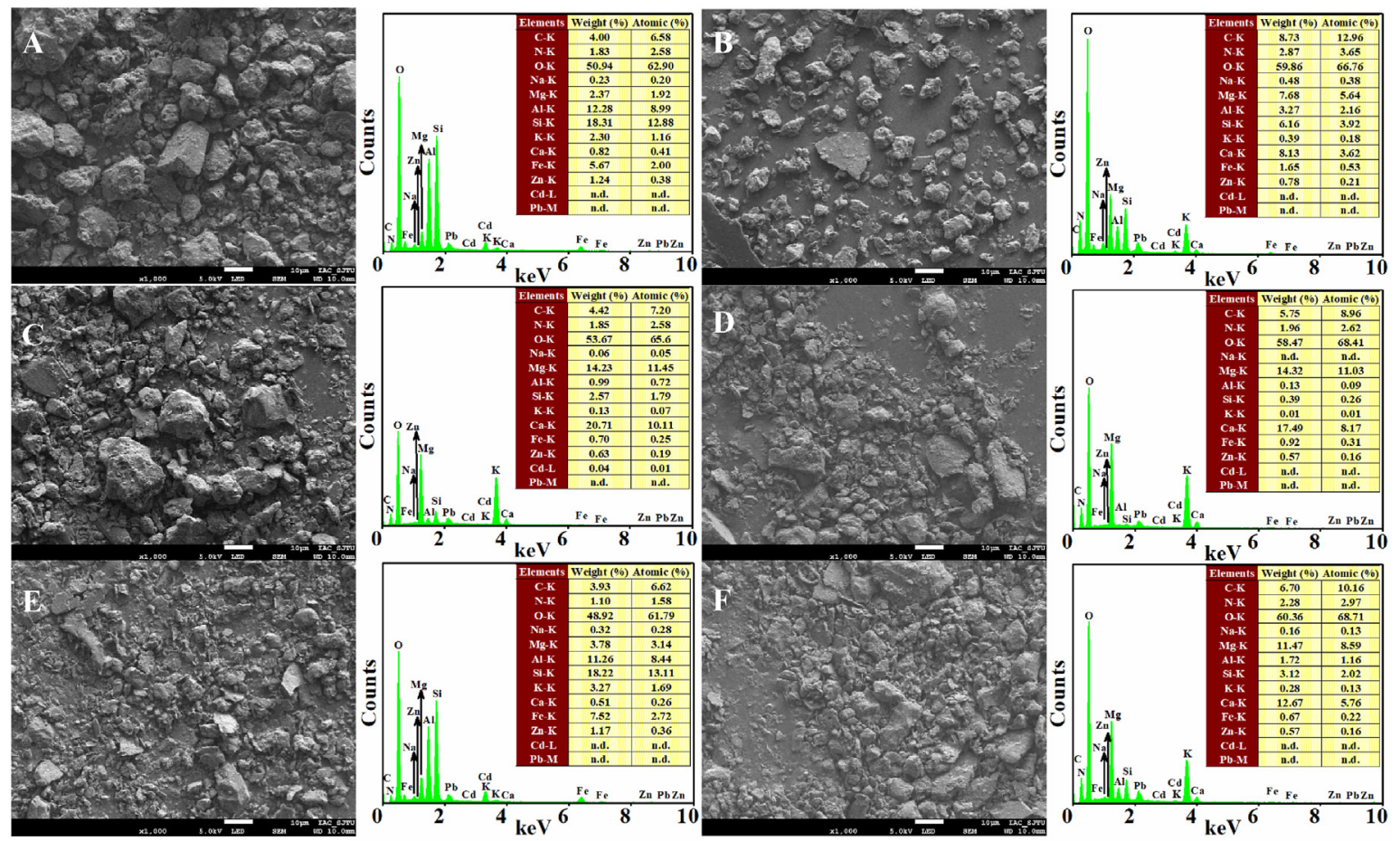

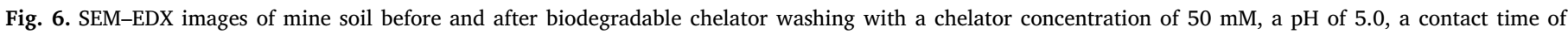

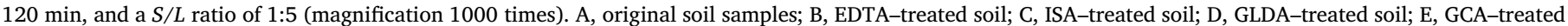
soil; and F, PASP-treated soil.

hosting metals. As compared with the SEM images after BC treatments of the mine soil, the EDTA treatment seemed to form some compact flocculent crystallized minerals on the microstructure of the soil particles (Fig. 6B). This suggests that EDTA washing caused a certain extent of soil corrosion. The EDX data further indicated that the major structural elements such as $\mathrm{O}, \mathrm{Si}, \mathrm{Mg}$, and $\mathrm{Al}$ were not washed out. However, the $\mathrm{Cd}$ and $\mathrm{Pb}$ containing compounds failed to be analyzed by EDX. This is because of their relatively low contents that were not sufficient for detection. The above-results illustrate that BC-induced washing had a limited influence on the soil texture and was involved in the complexation mechanism.

\subsection{3. $X R D$}

The XRD results of the bulk mine soil distinctly demonstrated the presence of quartz, dolomite, and feldspar (Fig. S6A). Wei et al. (2018) reported that washing of soil with a combination of EDTA and ascorbic acid could effectively destroy the binding bonds between heavy metal ions and amorphous iron oxides and poorly crystalline iron oxides. After reaction with EDTA and BCs, the XRD patterns of the mine soil showed no any unique changes, compared with the non-reacted soil. The ISA and GLDA induced relatively higher metal removal (Fig. 1), while EDTA could also complex multiple PTEs effectively (Begum et al., 2012; Tsang and Hartley, 2014; Chauhan et al., 2015; Sawai et al., 2017). The XRD patterns of the residues that were washed with EDTA, ISA, and GLDA identified that the dolomite patterns at $2 \theta$ of $24.10^{\circ}$, $63.56^{\circ}$, and $70.66^{\circ}$ partially disappeared and other mineral patterns, such as quartz and feldspar, were diminished conspicuously. The metal phases that were liberated and feebly bound on the soil colloid surface were effortlessly removed by BCs, and mineral dissolution was the rate-limiting of soil washing (Kim et al., 2015; Wei and Chen, 2016).

The dominant minerals of the polluted farmland soil were feldspar, quartz, kaolinite, and muscovite (Fig. 6B). The BC-induced washing had a great mineral dissolution capacity for muscovite and kaolinite. The new XRD peak at $2 \theta$ of $22.10^{\circ}$ appeared for the former, while the peaks at $2 \theta$ of $30.00^{\circ}, 35.17^{\circ}$, and $37.69^{\circ}$ disappeared and the new peaks at $2 \theta$ of $19.98^{\circ}$ and $55.33^{\circ}$ appeared for the latter, suggesting the formation and transformation of different crystalline phases during BC-induced washing, which would be conducive to promote the dissolution of minerals and the release of heavy metal ions from solid phase to liquid phase (Wei and Chen, 2016; Tang et al., 2017). In comparison with the untreated soils, the main peaks from both soils after washing did not appear offset and could still maintain a stable state which is consistent with previous reports (Mukhopadhyay et al., 2015; Zhang et al., 2017). This implies that the effect of BC-induced washing on mineral composition and crystal structure of soils was negligible.

\subsubsection{XPS}

To investigate the elemental composition and oxidation state of the soil samples after washing with EDTA and BCs (Kim and Baek, 2019; Ramrakhiani et al., 2019), XPS measurements were carried out. The XPS wide-scan survey of both bulk soils showed the presence of $\mathrm{Al} 2 \mathrm{p}$ (74.03 eV), Si 2p (102.25 eV), Pb 4f (138.85 eV), C 1s (285.01eV), Ca 2p (347.55 eV), Cd $3 \mathrm{~d}(415.02 \mathrm{eV}), \mathrm{O}$ 1s (531.40 eV), Fe 2p (711.42 eV), Zn 2p (1021.93 eV), and Mg 1s (1304.75 eV) (Fig. S7), which corroborated the results of SEM-EDS (Fig. 6 and Fig. S5) and XRD (Fig. S6).

The high-resolution XPS spectra of C $1 \mathrm{~s}, \mathrm{O} 1 \mathrm{~s}, \mathrm{Cd} 3 \mathrm{~d}, \mathrm{~Pb} 4 \mathrm{f}$, and $\mathrm{Zn}$ 2 p for both soils were further introduced (Fig. 7 and Fig. S8). The C $1 \mathrm{~s}$ spectra of untreated soils had four fitting peaks at binding energies (BEs) approximately of 284.6, 286.2, 288.9, and 292.8-296.0 eV, which could correspondingly be assigned to the presence of $\mathrm{C}-\mathrm{C}, \mathrm{C}-\mathrm{O}, \mathrm{C}=\mathrm{O}$, and C-F moieties (Khan et al., 2019; Ramrakhiani et al., 2019), respectively. Similarly, the $\mathrm{O} 1 \mathrm{~s}$ spectrum also deconvoluted into four peaks that corresponded to a different lattice oxygen state of the metal oxide $(530.5 \mathrm{eV}), \mathrm{C}=\mathrm{O}(531.3 \mathrm{eV}), \mathrm{C}-\mathrm{O}-\mathrm{C} / \mathrm{OH}(531.1 \mathrm{eV})$, and adsorbed $\mathrm{H}_{2} \mathrm{O}$ (532.9 eV) (Zhao et al., 2017; Lyu et al., 2018). After washing by EDTA and BCs, no characteristic peak appeared or disappeared and only the position of the peaks deviated by roughly $0.4 \mathrm{eV}$. However, the proportion of metal oxide decreased from the initial 

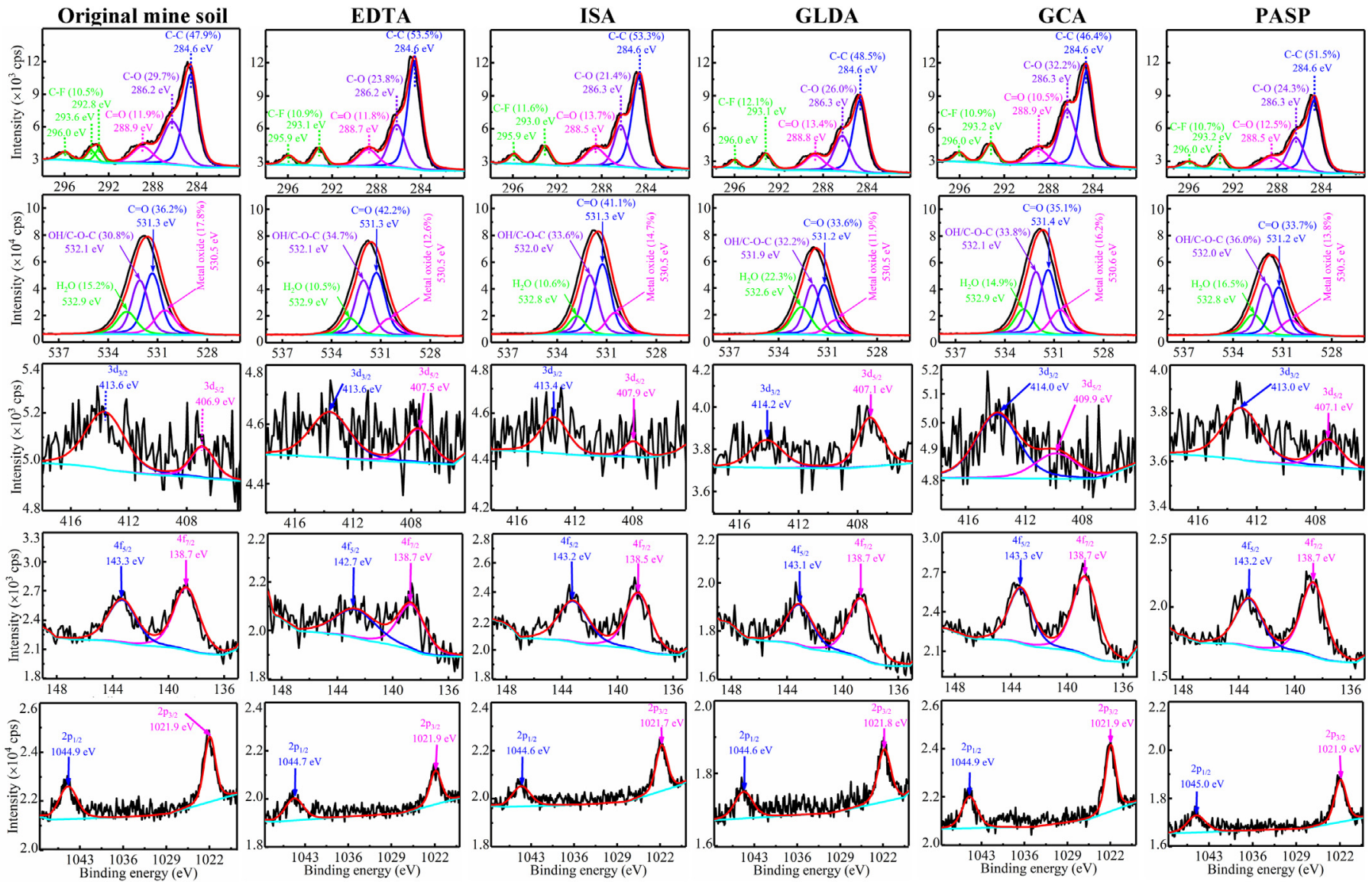

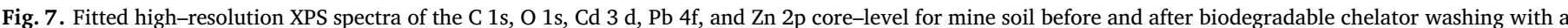

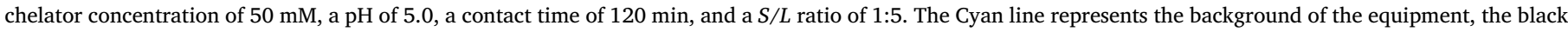

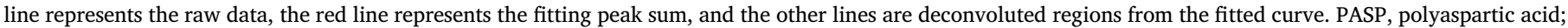

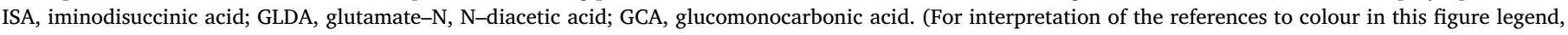
the reader is referred to the Web version of this article.)

$17.8 \%$ in mine soil to $11.9-16.2 \%$ and from the initial $18.8 \%$ in farmland soil to $10.7-18.4 \%$, which indicated that dissolution of oxides occurred. The $\mathrm{C} 1 \mathrm{~s}$ and $\mathrm{O} 1 \mathrm{~s}$ results showed no systematic changes of the assigned chemical states in the soils.

From the high-resolution XPS spectrum of Cd $3 \mathrm{~d}$, the peak located at BEs of $406.9 \mathrm{eV}$ from the original mine soil and $405.9 \mathrm{eV}$ from the original farmland soil was corresponded to $\mathrm{Cd} 3 \mathrm{~d} 5 / 2$, while the $\mathrm{Cd}$ $3 \mathrm{~d} 3 / 2$ could be accordingly obtained at BEs of 413.6 and $413.1 \mathrm{eV}$. Combined with the above XRD results of soils, these two sets of deconvoluted subpeaks with a peak separation of 6.8-7.2 eV between $\mathrm{Cd}$ $3 \mathrm{~d} 5 / 2$ and $\mathrm{Cd} 3 \mathrm{~d} 3 / 2$ states corresponded to the characteristic peaks of $\mathrm{Cd}^{2+}$ of $\mathrm{CdCO}_{3}$ (Lee et al., 2018) and $\mathrm{Cd}(\mathrm{OH})_{2}$ (Liang et al., 2014; Li et al., 2016), respectively. As for the soil $\mathrm{Pb} 4 \mathrm{f}$ spectrum, specific peaks located at BEs of 138.7 and $139.1 \mathrm{eV}(\mathrm{Pb} 4 \mathrm{f} 7 / 2)$ along with its satellite at $\mathrm{BEs}$ of 143.3 and $143.5 \mathrm{eV}$ ( $\mathrm{Pb} 4 \mathrm{f5} / 2$ ) corresponding to divalent states of $\mathrm{Pb}$ were detected (Li et al., 2018b). From Fig. 7 and Fig. S8, the broad peaks of $\mathrm{Zn} 2 \mathrm{p} 3 / 2$ located at BEs of 1021.9 and $1022.1 \mathrm{eV}$, and $\mathrm{Zn} 2 \mathrm{p} 1 / 2$ fitted at BEs of $1044.9 \mathrm{eV}$ for both soils. This is characteristic for the presence of $\mathrm{Zn}^{2+}$ (Li et al., 2016). After washing, the signal intensity from $\mathrm{Cd} 3 \mathrm{~d}, \mathrm{~Pb} 4 \mathrm{f}$, and $\mathrm{Zn} 2 \mathrm{p}$ decreased, indicating that readily accessible $\mathrm{Cd}, \mathrm{Pb}$, and $\mathrm{Zn}$ adsorbed or precipitated on the soil colloid surfaces was largely removed by EDTA and different BCs (Tsang and Hartley, 2014). Additionally, these characteristic peaks also did not exhibit a notable shift or disappearance in the washed soils, implying that no valence changes occurred where the oxides/precipitates of $\mathrm{Cd}$, $\mathrm{Pb}$, and $\mathrm{Zn}$ still remained on the soil colloid surfaces in the same chemical species (Kim et al., 2015; Wei et al., 2018).

\subsection{Potential mechanism of metal removal}

According to the above-mentioned results, the initial stage could be attributed to free $\mathrm{H}^{+}$from $\mathrm{BCs}$ that would improve the dissolution of metal (loid)s by dissolving alkaline oxides. ISA, GLDA, GCA, and PASP are all polydentate chelating agents with the following potential equilibrium states in the liquid phase (Eq. (4)-(7)) (Pinto et al., 2014).

$\mathrm{H}_{4} \mathrm{~L} \leftrightharpoons \mathrm{H}_{3}(\mathrm{~L})^{-}+\mathrm{H}^{+}$

$\mathrm{H}_{3}(\mathrm{~L})^{-} \leftrightharpoons \mathrm{H}_{2}(\mathrm{~L})^{2-}+\mathrm{H}^{+}$

$\mathrm{H}_{2}(\mathrm{~L})^{2-} \leftrightharpoons \mathrm{H}(\mathrm{L})^{3-}+\mathrm{H}^{+}$

$\mathrm{H}(\mathrm{L})^{3-} \leftrightharpoons \mathrm{L}^{4-}+\mathrm{H}^{+}$

where $L$ represents the four organic ligands.

In this study, the $\mathrm{pH} 5.0$ of BCs was recommended, which implies that the BCs were present in the form of $\mathrm{H}_{2}(\mathrm{~L})^{2-}$. The BCs were either protonated or deprotonated upon decreasing or increasing $\mathrm{pH}$ (Begum et al., 2012; Chauhan et al., 2015; Verma and Hait, 2019). The presence of protons interrupts the binding sites of PTEs in the soils, resulting in PTEs originally immobilized in the bimolecular layer of soil colloid being released into the liquid phase in the ionic form (Ferraro et al., 2016; Sawai et al., 2017).

Moreover, to understand the PTEs removal with the aid of BCs, the metal ion-ligand interaction should be considered. The reaction between the PTE ions $\left(\mathrm{M}^{2+}\right)$ and the anion of BCs is reversible and occurs at a ratio 1:1 as follows (Kołodyńska, 2011; Wu et al., 2015): 
$\mathrm{M}^{2+}+\mathrm{H}_{3}(\mathrm{~L})^{-} \leftrightharpoons\left[\mathrm{MH}_{3}(\mathrm{~L})\right]^{+}$

$\mathrm{M}^{2+}+\mathrm{H}_{2}(\mathrm{~L})^{2-} \leftrightharpoons\left[\mathrm{MH}_{2}(\mathrm{~L})\right]$

$\mathrm{M}^{2+}+\mathrm{H}(\mathrm{L})^{3-} \leftrightharpoons[\mathrm{MH}(\mathrm{L})]^{-}$

$\mathrm{M}^{2+}+\mathrm{L}^{4-} \leftrightharpoons[\mathrm{M}(\mathrm{L})]^{2-}$

The stability constant $(\log K)$ of the formation of metal-ligand complexes $(M-L)$ was further introduced. A higher $\log \mathrm{K}$ value reflects the increased stability of the $M-L$ complexes (Begum et al., 2012; Ferraro et al., 2016; Sanderson et al., 2017). As presented in Table S3, the sequence of theoretical removal efficiencies should be $\mathrm{Pb}>\mathrm{Zn}>$

Cd. However, the actual sequence of removal efficiencies as determined in our work was not in accordance with the trend exhibited above (Figs. 1-3 and S4). This is because the removal efficiencies of soil metals were also related to the dissolution rate of metal oxides, metal species, and the re-adsorption of $M-L$ complexes on soil particle surfaces (Nowack, 2002; Pinto et al., 2014).

The complexation processes between BCs and PTEs were through the synergistic incorporation of metal ions into the heterocyclic structures of the BCs, and the monodentate ligands were replaced by multidentate ligands to form $M-L$ complexes (Ferraro et al., 2016; Zhang and Zhou, 2019). These complexes were formed on the surface of soil particles and entered the liquid phase with maximum thermodynamic stability. Their transfer characteristics at the solid-liquid interface hinge upon external and internal diffusion mechanisms. The former includes rapid extraction of target PTEs from the surface of soil particles, while the latter means extraction of PTEs presented in the interior of the particles.

The BC-induced washing process could be divided into primary and secondary reactions due to the target heavy metals $\left(\mathrm{M}_{\mathrm{i}}^{\mathrm{m}^{\mathrm{i}}+}\right)$ and other components presented in the solid matrix. The primary reaction describes the $M-L$ interaction through the organic ligands $\left(L^{n-}, n=0,1,2\right.$, 3 , 4) substitution mechanism at the solid-liquid interface (Eq. (12)-(14)). The secondary reaction includes reabsorption of PTEs by either surface complexation (Eq. (15)) or ion-exchange reaction with other cationic species $\left(\mathrm{M}_{\mathrm{j}}^{\mathrm{m}_{\mathrm{j}}+}\right.$ ) (Eq. (16)-(17)) or existence in the liquid phase in the form of free state directly (Eq. (18)).

$($ soil $-O)-M_{i}^{m+}+L^{n-}+H_{2} O \leftrightharpoons($ soil $)-O H+M_{i}-L^{m+(n-1)-}+\mathrm{OH}^{-}$

$(\mathrm{OH})_{m} \mathrm{M}_{i}+\mathrm{L}^{n-} \leftrightharpoons \mathrm{M}_{i}-\mathrm{L}^{m+n-}+m \mathrm{OH}^{-}$

$\mathrm{M}_{i} \mathrm{O}\left(\mathrm{M}_{i} \mathrm{O}\right)^{m+2-}+\mathrm{L}^{n-}+\mathrm{H}_{2} \mathrm{O} \leftrightharpoons \mathrm{M}_{i}-\mathrm{L}^{m+n-}+2 \mathrm{OH}^{-}$

(soil) $-\mathrm{OH}+\mathrm{M}_{\mathrm{i}}^{\mathrm{m}+}-\mathrm{L}^{n-} \leftrightharpoons($ soil $)-\mathrm{L}^{(n-1)-}-\mathrm{M}_{\mathrm{i}}^{\mathrm{m+}}+\mathrm{OH}^{-}$

(soil) $-\mathrm{L}^{n-}-\mathrm{M}_{\mathrm{i}}^{\mathrm{m}_{\mathrm{i}}+}+($ soil $)-\mathrm{O}-\mathrm{M}_{\mathrm{j}}^{\mathrm{m}_{\mathrm{j}}+}+\mathrm{H}^{+} \leftrightharpoons$ (soil) $-\mathrm{L}^{n-}-\mathrm{M}_{\mathrm{j}}^{\mathrm{m}_{\mathrm{i}}+}$

$$
+(\text { soil })-\mathrm{OH}^{+}+\mathrm{Mi}_{\mathrm{i}}^{\mathrm{m}_{\mathrm{j}}+}
$$

(soil) $-\mathrm{L}^{n-}-\mathrm{M}_{\mathrm{j}}^{\mathrm{m}+}+\mathrm{OH}^{-} \leftrightharpoons($ soil $)-\mathrm{OH}+\mathrm{M}_{j}-\mathrm{L}^{m+(n+1)-}$

(soil) $-\mathrm{OH}+\mathrm{M}_{\mathrm{i}}^{\mathrm{m}+} \leftrightharpoons[($ soil $)-\mathrm{O}] \mathrm{M}_{\mathrm{i}}^{m+1-}+\mathrm{H}^{+}$

It could be inferred that the following mechanisms may take place for the removal of PTEs by BC-induced washing (Fig. 8): 1) the dissolution effect of metal oxides though; 2) the formed stable $M-L$ complexes sorption by soil organic matter (SOM) functional groups and linked to SOM/metal (oxy)hydroxide; 3) ion exchange with $\mathrm{K}^{+}$by electrostatic outer-sphere complexation and exchange with $\mathrm{Ca}^{2+}$ by inner-sphere complexation and co-precipitation; and 4) surface complexation of PTEs by the available complexing sites of BCs.

\section{Conclusions}

The removal efficiencies and mechanisms of $\mathrm{Cd}, \mathrm{Pb}$, and $\mathrm{Zn}$ with the biodegradable chelators GCA, GLDA, PASP, and ISA were studied in

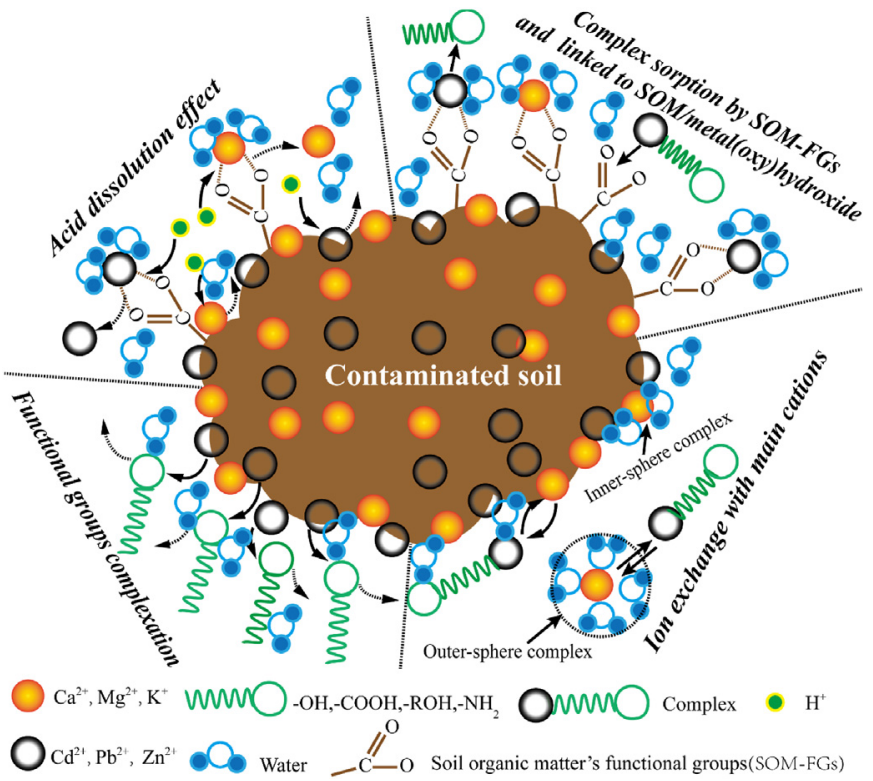

Fig. 8. Schematic of the potential mechanisms of heavy metals removal from polluted soil by biodegradable chelator washing.

real mine soil and polluted farmland soil. The chelators achieved higher $\mathrm{Cd}, \mathrm{Pb}$, and $\mathrm{Zn}$ removal efficiencies than the control treatment of wateronly washing. The $\mathrm{Cd}, \mathrm{Pb}$, and $\mathrm{Zn}$ removal efficiencies generally increased with the raised of concentrations of biodegradable chelator, contact time, and $S / L$ ratio within certain limits. They were most noticeable at weakly acidic to neutral solution $\mathrm{pH}$ values. The intensity of heavy metal binding to soil colloids increased while the metal mobility reduced because of weakly bound fractions such as water-soluble, exchangeable, and carbonate bound fractions were removed by biodegradable chelators. The dominant mechanism of removal of heavy metals to biodegradable chelators included acid dissolution, ion exchange, and surface complexation. This work has shown that biodegradable chelators, especially ISA and GLDA, as alternatives to non-biodegradable EDTA, provided an effective approach to enhance heavy metals removal from polluted soils. Further investigations that explore the effect of biodegradable chelator-induced washing on the ecological status of remediated soils are needed.

\section{Funding sources supporting the work}

This work was supported by the Sichuan International Science and Technology Innovation Cooperation/Hong Kong, Macao and Taiwan Science and Technology Innovation Cooperation Project, Sichuan, China (2020GJHZ0067) and the Projects of the Key Research and Development Program of Sichuan Province, China (2019YFN0020).

\section{CRediT authorship contribution statement}

Guiyin Wang: Writing - original draft, Writing - review \& editing. Xiaomei Pan: Writing - original draft, Writing - review \& editing. Shirong Zhang: Writing - original draft, Writing - review \& editing. Qinmei Zhong: Formal analysis. Wei Zhou: Formal analysis. Xiaohong Zhang: Writing - review \& editing. Jun Wu: Writing - review \& editing. Martina G. Vijver: Writing - review \& editing. Willie J.G.M. Peijnenburg: Writing - review \& editing.

\section{Declaration of competing interest}

The authors declare there is no conflict of interest in this work. 


\section{Acknowledgments}

This work was supported by the Sichuan International Science and Technology Innovation Cooperation/Hong Kong, Macao and Taiwan Science and Technology Innovation Cooperation Project, Sichuan, China (2020GJHZ0067) and the Projects of the Key Research and Development Program of Sichuan Province, China (2019YFN0020). The authors thank Weijin Feng, Ximeng Liu, Ruiqi Zhang, Can Feng, and Xiaojie Ma of Sichuan Agricultural University, for supporting the analysis work.

\section{Appendix A. Supplementary data}

Supplementary data to this article can be found online at https:// doi.org/10.1016/j.envres.2020.109554.

\section{References}

Abou-El-Sherbini, K.S., Elzahany, E.A.M., Wahba, M.A., Drweesh, S.A., Youssef, N.S., 2017. Evaluation of some intercalation methods of dimethylsulphoxide onto HCltreated and untreated Egyptian kaolinite. Appl. Clay Sci. 137, 33-42.

Begum, Z.A., Rahman, I.M.M., Tate, Y., Sawai, H., Maki, T., Hasegawa, H., 2012. Remediation of toxic metal contaminated soil by washing with biodegradable aminopolycarboxylate chelants. Chemosphere 87 (10), 1161-1170.

Begum, Z.A., Rahman, I.M.M., Ishii, K., Tsukada, H., Hasegawa, H., 2020. Dynamics of strontium and geochemically correlated elements in soil during washing remediation with eco-complaint chelators. J. Environ. Manag. 259, 110018.

Beiyuan, J., Tsang, D.C.W., Bolan, N.S., Baek, K., Ok, Y.S., Li, X., 2018. Interactions of food waste compost with metals and metal-chelant complexes during soil remediation. J. Clean. Prod. 192, 199-206.

Beiyuan, J., Tsang, D.C.W., Valix, M., Zhang, W., Yang, X., Ok, Y.S., Li, X., 2017. Selective dissolution followed by EDDS washing of an e-waste contaminated soil: extraction efficiency, fate of residual metals, and impact on soil environment. Chemosphere 166, 489-496.

Borggaard, O.K., Holm, P.E., Strobel, B.W., 2019. Potential of dissolved organic matter (DOM) to extract $\mathrm{As}, \mathrm{Cd}, \mathrm{Co}, \mathrm{Cr}, \mathrm{Cu}, \mathrm{Ni}, \mathrm{Pb}$ and $\mathrm{Zn}$ from polluted soils: a review. Geoderma 343, 235-246.

Cao, Y., Qian, X., Zhang, Y., Qu, G., Xia, T., Guo, X., Jia, H., Wang, T., 2019. Decomplexation of EDTA-chelated copper and removal of copper ions by non-thermal plasma oxidation/alkaline precipitation. Chem. Eng. J. 362, 487-496.

Chauhan, G., Pant, K.K., Nigam, K.D.P., 2015. Chelation technology: a promising green approach for resource management and waste minimization. Environ. Sci. J. Integr. Environ. Res.: Processes \& Impacts 17 (1), 12-40.

Długosz, O., Banach, M., 2018. Kinetic, isotherm and thermodynamic investigations of the adsorption of $\mathrm{Ag}^{+}$and $\mathrm{Cu}^{2+}$ on vermiculite. J. Mol. Liq. 258, 295-309.

Dolev, N., Katz, Z., Ludmer, Z., Ullmann, A., Brauner, N., Goikhman, R., 2019. New insights into chelator recycling by a chelating resin: from molecular mechanisms to applicability. Chemosphere 215, 800-806.

Dolev, N., Katz, Z., Ludmer, Z., Ullmann, A., Brauner, N., Goikhman, R., 2020. Natural amino acids as potential chelators for soil remediation. Environ. Res. 183, 109140.

Ferraro, A., Fabbricino, M., van Hullebusch, E.D., Esposito, G., Pirozzi, F., 2016. Effect of soil/contamination characteristics and process operational conditions on aminopolycarboxylates enhanced soil washing for heavy metals removal: a review. Rev. Environ. Sci. Biotechnol. 15 (1), 111-145.

Feng, W., Zhang, S., Zhong, Q., Wang, G., Pan, X., Xu, X., Zhou, W., Li, T., Luo, L., Zhang, Y., 2020. Soil washing remediation of heavy metal from contaminated soil with EDTMP and PAA: properties, optimization, and risk assessment. J. Hazard Mater 381, 120997.

Gan, X., Teng, Y., Ren, W., Ma, J., Christie, P., Luo, Y., 2017. Optimization of ex-situ washing removal of polycyclic aromatic hydrocarbons from a contaminated soil using nano-sulfonated graphene. Pedosphere 27 (3), 527-536.

Gluhar, S., Jez, E., Lestan, D., 2019. The use of zero-valent Fe for curbing toxic emissions after EDTA-based washing of $\mathrm{Pb}, \mathrm{Zn}$ and $\mathrm{Cd}$ contaminated calcareous and acidic soil. Chemosphere 215, 482-489.

Golmaei, M., Kinnarinen, T., Jernström, E., Häkkinen, A., 2018. Extraction of hazardous metals from green liquor dregs by ethylenediaminetetraacetic acid. J. Environ. Manag. 212, 219-227.

Gusiatin, Z.M., Kulikowska, D., Klik, B., 2017. Suitability of humic substances recovered from sewage sludge to remedy soils from a former as mining area-A novel approach. J. Hazard Mater. 338, 160-166.

Hasegawa, H., Mamun, M.A.A., Tsukagoshi, Y., Ishii, K., Sawai, H., Begum, Z.A., Asami, M.S., Maki, T., Rahman, I.M.M., 2019. Chelator-assisted washing for the extraction of lead, copper, and zinc from contaminated soils: a remediation approach. Appl. Geochem. 109, 104397.

Hisada, M., Kawase, Y., 2018. Recovery of rare-earth metal neodymium from aqueous solutions by poly- $\gamma$-glutamic acid and its sodium salt as biosorbents: effects of solution pH on neodymium recovery mechanisms. J. Rare Earths 36 (5), 528-536.

Im, J., Yang, K., Jho, E.H., Nam, K., 2015. Effect of different soil washing solutions on bioavailability of residual arsenic in soils and soil properties. Chemosphere 138, 253-258.
Jho, E.H., Im, J., Yang, K., Kim, Y., Nam, K., 2015. Changes in soil toxicity by phosphateaided soil washing: effect of soil characteristics, chemical forms of arsenic, and cations in washing solutions. Chemosphere 119, 1399-1405.

Khan, F., Oh, M., Kim, J.H., 2019. N-functionalized graphene quantum dots: charge transporting layer for high-rate and durable $\mathrm{Li}_{4} \mathrm{Ti}_{5} \mathrm{O}_{12}$-based Li-ion battery. Chem. Eng. J. 369, 1024-1033.

Kim, E.J., Baek, K., 2019. Selective recovery of ferrous oxalate and removal of arsenic and other metals from soil-washing wastewater using a reduction reaction. J. Clean. Prod. 221, 635-643.

Kim, E.J., Lee, J., Baek, K., 2015. Abiotic reductive extraction of arsenic from contaminated soils enhanced by complexation: arsenic extraction by reducing agents and combination of reducing and chelating agents. J. Hazard Mater. 283, 454-461.

Kirpichtchikova, T.A., Manceau, A., Spadini, L., Panfili, F., Marcus, M.A., Jacquet, T., 2006. Speciation and solubility of heavy metals in contaminated soil using X-ray microfluorescence, EXAFS spectroscopy, chemical extraction, and thermodynamic modeling. Geochem. Cosmochim. Acta 70 (9), 2163-2190.

Kołodyńska, D., 2011. Cu(II), Zn(II), Co(II) and Pb(II) removal in the presence of the complexing agent of a new generation. Desalination 267 (2-3), 175-183.

Kulikowska, D., Gusiatin, Z.M., Bułkowska, K., Klik, B., 2015. Feasibility of using humic substances from compost to remove heavy metals ( $\mathrm{Cd}, \mathrm{Cu}, \mathrm{Ni}, \mathrm{Pb}, \mathrm{Zn}$ ) from contaminated soil aged for different periods of time. J. Hazard Mater. 300, 882-891.

Kulikowska, D., Klik, B.K., Gusiatin, Z.M., Jabłoński, R., 2019. Sewage sludge can provide a washing agent for remediation of soil from a metallurgical area. Catena 173, 22-28.

Lee, H.H., Owens, V.N., Park, S., Kim, J., Hong, C.O., 2018. Adsorption and precipitation of cadmium affected by chemical form and addition rate of phosphate in soils having different levels of cadmium. Chemosphere 206, 369-375.

Li, J., Chen, Z., Wang, Q., Fang, L., Xue, Q., Cheeseman, C.R., Donatello, S., Liu, L., Poon, C.S., 2018a. Change in re-use value of incinerated sewage sludge ash due to chemical extraction of phosphorus. Waste Manag. 74, 404-412.

Li, X., Wu, Y., Zhang, C., Liu, Y., Zeng, G., Tang, X., Dai, L., Lan, S., 2016. Immobilizing of heavy metals in sediments contaminated by nonferrous metals smelting plant sewage with sulfate reducing bacteria and micro zero valent iron. Chem. Eng. J. 306, 393-400.

Li, Z., Wang, L., Meng, J., Liu, X., Xu, J., Wang, F., Brookes, P., 2018b. Zeolite-supported nanoscale zero-valent iron: new findings on simultaneous adsorption of $\mathrm{Cd}(\mathrm{II}), \mathrm{Pb}(\mathrm{II})$, and As(III) in aqueous solution and soil. J. Hazard Mater. 344, 1-11.

Liang, X., Han, J., Xu, Y., Sun, Y., Wang, L., Tan, X., 2014. In situ field-scale remediation of Cd polluted paddy soil using sepiolite and palygorskite. Geoderma 235-236, 9-18.

Liu, Q., Deng, Y., Tang, J., Chen, D., Li, X., Lin, Q., Yin, G., Zhang, M., Hu, H., 2019. Potassium lignosulfonate as a washing agent for remediating lead and copper cocontaminated soils. Sci. Total Environ. 658, 836-842.

Lyu, H., Zhao, H., Tang, J., Gong, Y., Huang, Y., Wu, Q., Gao, B., 2018. Immobilization of hexavalent chromium in contaminated soils using biochar supported nanoscale iron sulfide composite. Chemosphere 194, 360-369.

Medina, J., Monreal, C., Chabot, D., Meier, S., González, M.E., Morales, E., Parillo, R. Borie, F., Cornejo, P., 2017. Microscopic and spectroscopic characterization of humic substances from a compost amended copper contaminated soil: main features and their potential effects on Cu immobilization. Environ. Sci. Pollut. Res. 24 (16), 14104-14116.

Meng, F., Yuan, G., Wei, J., Bi, D., Ok, Y.S., Wang, H., 2017. Humic substances as a washing agent for Cd-contaminated soils. Chemosphere 181, 461-467.

Mu Azu, N.D., Haladu, S.A., Jarrah, N., Zubair, M., Essa, M.H., Ali, S.A., 2018. Polyaspartate extraction of cadmium ions from contaminated soil: evaluation and optimization using central composite design. J. Hazard Mater. 342, 58-68.

Mukhopadhyay, S., Mukherjee, S., Hashim, M.A., Sen Gupta, B., 2015. Application of colloidal gas aphron suspensions produced from Sapindus mukorossi for arsenic removal from contaminated soil. Chemosphere 119, 355-362.

Nowack, B., 2002. Environmental chemistry of aminopolycarboxylate chelating agents. Environ. Sci. Technol. 36 (19), 4009-4016.

Parolo, M.E., Savini, M.C., Loewy, R.M., 2017. Characterization of soil organic matter by FT-IR spectroscopy and its relationship with chlorpyrifos sorption. J. Environ. Manag. 196, 316-322.

Piccolo, A., Spaccini, R., De Martino, A., Scognamiglio, F., di Meo, V., 2019. Soil washing with solutions of humic substances from manure compost removes heavy metal contaminants as a function of humic molecular composition. Chemosphere 225, $150-156$.

Pinto, I.S.S., Neto, I.F.F., Soares, H.M.V.M., 2014. Biodegradable chelating agents for industrial, domestic, and agricultural applications-a review. Environ. Sci. Pollut. Res. 21 (20), 11893-11906.

Ramrakhiani, L., Ghosh, S., Mandal, A.K., Majumdar, S., 2019. Utilization of multi-metal laden spent biosorbent for removal of glyphosate herbicide from aqueous solution and its mechanism elucidation. Chem. Eng. J. 361, 1063-1077.

Rui, D., Wu, Z., Ji, M., Liu, J., Wang, S., Ito, Y., 2019. Remediation of Cd- and Pb- contaminated clay soils through combined freeze-thaw and soil washing. J. Hazard Mater. 369, 87-95.

Sanderson, P., Naidu, R., Bolan, N., 2017. Application of a biodegradable chelate to enhance subsequent chemical stabilisation of $\mathrm{Pb}$ in shooting range soils. J. Soils Sediments 17 (6), 1696-1705.

Sawai, H., Rahman, I.M.M., Lu, C., Begum, Z.A., Saito, M., Hasegawa, H., 2017. Extractive decontamination of cesium-containing soil using a biodegradable aminopolycarboxylate chelator. Microchem. J. 134, 230-236.

Shen, Z., Zhang, J., Hou, D., Tsang, D.C.W., Ok, Y.S., Alessi, D.S., 2019. Synthesis of MgOcoated corncob biochar and its application in lead stabilization in a soil washing residue. Environ. Int. 122, 357-362.

Suanon, F., Sun, Q., Dimon, B., Mama, D., Yu, C., 2016. Heavy metal removal from sludge with organic chelators: comparative study of N, N-bis(carboxymethyl) glutamic acid 
and citric acid. J. Environ. Manag. 166, 341-347.

Tandy, S., Ammann, A., Schulin, R., Nowack, B., 2006. Biodegradation and speciation of residual SS-ethylenediaminedisuccinic acid (EDDS) in soil solution left after soil washing. Environ. Pollut. 142 (2), 191-199.

Tang, J., He, J., Liu, T., Xin, X., 2017. Removal of heavy metals with sequential sludge washing techniques using saponin: optimization conditions, kinetics, removal effectiveness, binding intensity, mobility and mechanism. RSC Adv. 7, 33385.

Tessier, A., Campbell, P., Bisson, M., 1979. Sequential extraction procedure for the speciation of particulate trace metals. Anal. Chem. 7 (51), 844-851.

Tsang, D.C.W., Hartley, N.R., 2014. Metal distribution and spectroscopic analysis after soil washing with chelating agents and humic substances. Environ. Sci. Pollut. Res. 21 (5), 3987-3995.

Verma, A., Hait, S., 2019. Chelating extraction of metals from e-waste using diethylene triamine pentaacetic acid. Process Saf. Environ. 121, 1-11.

Wang, G., Zhang, S., Xu, X., Zhong, Q., Zhang, C., Jia, Y., Li, T., Deng, O., Li, Y., 2016. Heavy metal removal by GLDA washing: optimization, redistribution, recycling, and changes in soil fertility. Sci. Total Environ. 569-570, 557-568.

Wang, G., Zhang, S., Zhong, Q., Peijnenburg, W.J.G.M., Vijver, M.G., 2018a. Feasibility of Chinese cabbage (Brassica bara) and lettuce (Lactuca sativa) cultivation in heavily metals - contaminated soil after washing with biodegradable chelators. J. Clean. Prod. 197, 479-490.

Wang, G., Zhang, S., Zhong, Q., Xu, X., Li, T., Jia, Y., Zhang, Y., Peijnenburg, W.J.G.M., Vijver, M.G., 2018b. Effect of soil washing with biodegradable chelators on the toxicity of residual metals and soil biological properties. Sci. Total Environ. 625, 1021-1029.

Wang, K., Liu, Y., Song, Z., Khan, Z., Qiu, W., 2019. Effects of biodegradable chelator combination on potentially toxic metals leaching efficiency in agricultural soils. Ecotoxicol. Environ. Saf. 182, 109399.

Wei, M., Chen, J., 2016. Influence of multi-step washing using $\mathrm{Na}_{2}$ EDTA, oxalic acid and phosphoric acid on metal fractionation and spectroscopy characteristics from contaminated soil. Environ. Sci. Pollut. Res. 23 (22), 23123-23133.

Wei, M., Chen, J., Wang, Q., 2018. Remediation of sandy soil contaminated by heavy metals with $\mathrm{Na}_{2}$ EDTA washing enhanced with organic reducing agents: element distribution and spectroscopic analysis. Eur. J. Soil Sci. 69 (4), 719-731.

Wen, J., Li, Z., Huang, B., Luo, N., Huang, M., Yang, R., Zhang, Q., Zhai, X., Zeng, G., 2018. The complexation of rhizosphere and nonrhizosphere soil organic matter with chromium: using elemental analysis combined with FTIR spectroscopy. Ecotoxicol. Environ. Saf. 154, 52-58.

Wu, Q., Cui, Y., Li, Q., Sun, J., 2015. Effective removal of heavy metals from industrial sludge with the aid of a biodegradable chelating ligand GLDA. J. Hazard Mater. 283, $748-754$.

Yang, T., Hodson, M.E., 2019. Investigating the use of synthetic humic-like acid as a soi washing treatment for metal contaminated soil. Sci. Total Environ. 647, 290-300.

Zeino, A., Abdulazeez, I., Khaled, M., Jawich, M.W., Obot, I.B., 2018. Mechanistic study of polyaspartic acid (PASP) as eco-friendly corrosion inhibitor on mild steel in 3\% $\mathrm{NaCl}$ aerated solution. J. Mol. Liq. 250, 50-62.

Zhang, H., Gao, Y., Xiong, H., 2017. Removal of heavy metals from polluted soil using the citric acid fermentation broth: a promising washing agent. Environ. Sci. Pollut. Res. 24 (10), 9506-9514.

Zhang, S., Wen, J., Hu, Y., Fang, Y., Zhang, H., Xing, L., Wang, Y., Zeng, G., 2019. Humic substances from green waste compost: an effective washing agent for heavy metal (Cd, Ni) removal from contaminated sediments. J. Hazard Mater. 366, 210-218.

Zhang, Y., Zhou, M., 2019. A critical review of the application of chelating agents to enable Fenton and Fenton-like reactions at high pH values. J. Hazard Mater. 362, $436-450$.

Zhao, X., Wang, Y., Wu, H., Fang, L., Liang, J., Fan, Q., Li, P., 2017. Insights into the effect of humic acid on Ni(II) sorption mechanism on illite: batch, XPS and EXAFS investigations. J. Mol. Liq. 248, 1030-1038. 